\title{
Characterization of Depolarization-Induced Suppression of Inhibition Using Paired Interneuron-Purkinje Cell Recordings
}

\author{
Marco A. Diana and Alain Marty \\ Laboratoire de Physiologie Cérébrale, Université Paris 5, 75006 Paris, France
}

\begin{abstract}
Depolarization-induced suppression of inhibition (DSI) is a retrograde form of synaptic inhibition involving the $\mathrm{Ca}^{2+}$-dependent release of cannabinoids from the postsynaptic cell. DSI exerts multiple effects on presynaptic neurons: here, we establish the breakdown of DSI in its individual components at the synapses between basket and stellate cells and Purkinje cells. In the presence of tetrodotoxin, the change in IPSC frequency entirely accounted for the decrease of transmission during DSI; in contrast, without tetrodotoxin, the reductions of frequency and average amplitude gave equal contributions. In paired recordings, transmission displayed an irreversible rundown unless interneurons were recorded from with the perforated patch method. Under these conditions, a DSI of $68.8 \%$ was measured; the failure rate and the paired pulse ratio (at 20 msec intervals) increased from 1.2 to 20.2 and 95.6 to $132.6 \%$, respectively, and the variance to mean ratio augmented 2.17-fold. Presynaptic dialysis with $\mathrm{Cs}^{+}$led to a major potentiation of synaptic strength and to a marked reduction of DSI with respect to control potassium conditions; DSI recovered only partially when decreasing the extracellular $\mathrm{Ca}^{2+}$ concentration to match the control IPSC amplitudes. These results, combined with those of Kreitzer et al. (2002), indicate that three distinct presynaptic processes contribute to DSI: reductions of miniature frequency ( $13.4 \%$ of total DSI), of presynaptic action potential frequency (23.2\%), and of the probability that presynaptic depolarizations elicit transmitter release (63.4\%). The latter component involves a modulation of $\mathrm{K}^{+}$channels and trial-to-trial modifications of the presynaptic signal.
\end{abstract}

Key words: DSI in various components; paired recordings; perforated patch; GABAergic interneurons; retrograde communication; cerebellum

\section{Introduction}

Depolarization-induced suppression of inhibition (DSI) is a form of short-term synaptic plasticity that involves the calciumdependent release of a retrograde messenger on postsynaptic depolarization (Llano et al., 1991; Pitler and Alger, 1992, 1994; Vincent et al., 1992). DSI is observed with similar properties in cerebellar Purkinje cells and in hippocampal CA1 pyramidal cells. In both instances, the modulated synaptic currents are IPSCs originating in interneurons (stellate and basket cells in the cerebellum). DSI does not appear to involve modifications of postsynaptic receptors (Llano et al., 1991; Pitler and Alger, 1992) but, rather, a decrease in the amount of released neurotransmitter (Vincent et al., 1992; Alger et al., 1996).

Recent results indicate that both hippocampal and cerebellar DSI are mediated by the release of endogenous cannabinoids from the postsynaptic cell and by the consequent activation of cannabinoid receptors of the cannabinoid 1 receptor $(\mathrm{CB} 1 \mathrm{R})$

\footnotetext{
Received Dec. 11, 2002; revised Feb. 21, 2003; accepted April 12, 2003.

M.A.D. was supported by European Community Grants ERBFMRXCT980236 and QLG3-CT-2001-02430 and by the Boehringer Ingelheim Foundation. Most of this work was performed in the Department of Cellular Neurobiology, Max-Planck-Institute for Biophysical Chemistry (Goettingen, Germany). We are grateful to the Max-Planck-Society for support. We thank Dr. Christophe Pouzat for sharing analysis software.

Correspondence should be addressed to Dr. Alain Marty, Laboratoire de Physiologie Cérébrale, Université Paris 5 , 45 rue des Saints Pères, 75270 Paris Cedex 06, France. E-mail: amarty@biomedicale.univ-paris5.fr.

Copyright $\odot 2003$ Society for Neuroscience $\quad$ 0270-6474/03/235906-13\$15.00/0
}

subtype in the presynaptic terminals (Wilson and Nicoll, 2001; Kreitzer and Regehr, 2001; Diana et al., 2002; Yoshida et al., 2002). In various preparations, CB1Rs are known to modify adenylate cyclase as well as a host of $\mathrm{K}^{+}$- and $\mathrm{Ca}^{2+}$-selective channels (Ameri, 1999). However, the exact mode of action of CB1Rs during DSI remains elusive.

The results of previous studies have indicated that, during cerebellar DSI, several distinct processes contribute to reduce the release from GABAergic terminals: (1) the frequency of miniature IPSCs (mIPSCs) decreases, which indicates a direct effect on exocytosis, because an mIPSC frequency is not altered by blockers of voltage-dependent $\mathrm{Ca}^{2+}$ channels (Llano et al., 2000); (2) the rate of firing of presynaptic cells decreases, apparently because of the modulation of a $\mathrm{K}^{+}$current (Kreitzer et al., 2002), and this could account for the lateral spread of DSI in the molecular layer (Vincent and Marty, 1993); and (3) the $\mathrm{Ca}^{2+}$ transient amplitude measured at presynaptic release sites in response to short trains of action potentials decreases during DSI (Diana et al., 2002), possibly because of a modulation of voltage-dependent $\mathrm{Ca}^{2+}$ channels (Wilson et al., 2001). All of these effects are attributable to the activation of presynaptic CB1Rs, and they occur at least approximately within the same period. However, the specific share of each of these processes in the overall inhibition is unknown.

To sort out the role of these various components, we have reinvestigated the amount and time course of cerebellar DSI in 
various experimental conditions. One limitation of previous DSI studies is that they dealt primarily on evoked synaptic currents resulting from extracellular stimulations. It is virtually impossible to separate processes 2 and 3 with such methods, particularly because the newly uncovered modification of presynaptic excitability (Kreitzer et al., 2002) may lead to failures to excite the presynaptic cell(s) during extracellular stimulation protocols. Hence, we have focused our work on paired recordings because this approach gives unequivocal control of presynaptic firing. Using paired recordings, we have also investigated the effects of replacing the intracellular $\mathrm{K}^{+}$with $\mathrm{Cs}^{+}$in the presynaptic cell to explore the possibility that DSI may involve the modulation of $\mathrm{K}^{+}$channels.

\section{Materials and Methods}

Preparation. All experiments were performed on slices obtained from the cerebellar vermis of 11- to 15-d-old Wistar rats. After decapitation, cerebella were rapidly extracted and cooled in $3-5^{\circ} \mathrm{C}$ cold bicarbonatebuffered saline (BBS) for a few minutes. One hundred eightymicrometer-thick sagittal sections were cut using a Leica (Nussloch, Germany) VT1000S Vibratome in cold BBS; they were left to recover before use for $1 \mathrm{hr}$ in $\mathrm{BBS}$ at $34^{\circ} \mathrm{C}$ and, finally, at room temperature for the remaining experimental day. Once transferred into the recording chamber, the slices were continuously perfused with oxygenated BBS at a rate of $1-1.5 \mathrm{ml} / \mathrm{min}$ at room temperature. An Axioscope upright microscope (Zeiss, Oberkochen, Germany) with differential interference optics, a $63 \times, 0.9$ numerical aperture (NA) water immersion objective, and a 0.63 NA condenser was used to identify Purkinje cells and presynaptic GABAergic interneurons.

Solutions. BBS contained (in mM): $125 \mathrm{NaCl}, 2.5 \mathrm{KCl}, 2 \mathrm{CaCl}_{2}, 1$ $\mathrm{MgCl}_{2}, 1.25 \mathrm{NaH}_{2} \mathrm{PO}_{4}, 26 \mathrm{NaHCO}_{3}$, and 10 glucose, $\mathrm{pH} 7.4$, equilibrated by continuously bubbling with $95 \% \mathrm{O}_{2}$ and $5 \% \mathrm{CO}_{2}$. For low calcium experiments, the concentration of $\mathrm{CaCl}_{2}$ was decreased to $1 \mathrm{~mm}$, whereas that of $\mathrm{MgCl}_{2}$ was increased to $4 \mathrm{~mm}$; the concentrations for the other chemicals (all from Sigma, St. Louis, MO) were not modified. In all experiments, ionotropic glutamatergic transmission was blocked by NBQX (2-10 $\mu \mathrm{M}$; Tocris Cookson, Bristol, UK) and AP-V (50 $\mu \mathrm{M}$; Tocris Cookson); to record mIPSCs, TTX (200-500 nM; Sigma) was used. All drugs were directly added to the bath BBS.

Electrophysiological recordings. Experiments were performed with a double EPC-9 amplifier (HEKA, Lambrecht, Germany). Recording pipettes were pulled from borosilicate glass capillaries (Purkinje cells, 2-2.8 $\mathrm{M} \Omega$; interneurons, 5-7 $\mathrm{M} \Omega$ for whole-cell and 8-12 $\mathrm{M} \Omega$ for perforated patch recordings). Purkinje cells were whole-cell voltage clamped using the following intracellular solution (in $\mathrm{mm}$ ): $150 \mathrm{CsCl}, 4.6 \mathrm{MgCl}_{2}, 0.1$ $\mathrm{CaCl}_{2}, 10$ HEPES, 1 EGTA, 4 Na-ATP, and 0.4 Na-GTP. The holding potential was kept at -60 to $-70 \mathrm{mV}$, giving rise to inward GABAergic currents. For paired recordings, the perforated patch configuration for presynaptic interneurons was achieved by adding amphotericin B (300 $\mu \mathrm{g} / \mathrm{ml}$, previously aliquoted in DMSO) to the following solutions (in mM): 150 K-gluconate, $4.6 \mathrm{MgCl}_{2}, 0.1 \mathrm{CaCl}_{2}, 10 \mathrm{HEPES}, 1 \mathrm{EGTA}, 4$ $\mathrm{Na}-\mathrm{ATP}$, and 0.4 Na-GTP; for the cesium experiments, Cs-gluconate $(150 \mathrm{~mm})$ replaced K-gluconate.

Presynaptic cells were voltage clamped at -70 to $-80 \mathrm{mV}$; unclamped action potentials were triggered by short $(3-10 \mathrm{msec})$ depolarizations to +10 or $0 \mathrm{mV}$. In experiments with presynaptically $\mathrm{Cs}^{+}$-dialyzed interneurons, depolarizations were followed by $10-50 \mathrm{msec}$ hyperpolarizing steps to $-100 \mathrm{mV}$ to help axonal repolarization. In a few earlier experiments, interneurons were stimulated at 0.5 or $0.33 \mathrm{~Hz}$; otherwise, stimulation rate was $0.2 \mathrm{~Hz}$.

In some paired recording experiments, a paired pulse protocol was applied by stimulating interneurons twice at 20 msec intervals in presynaptic potassium or at $100 \mathrm{msec}$ intervals in presynaptic cesium. For these trials, paired evoked IPSCs (eIPSCs) were always elicited at $0.2 \mathrm{~Hz}$.

Data were sampled at $5 \mathrm{kHz}$ and filtered at $1 \mathrm{kHz}$.

Data analysis. DSI was induced by depolarizing Purkinje cells either with eight steps to $0 \mathrm{mV}$ for $100 \mathrm{msec}$ at $1 \mathrm{~Hz}$ or with a single step to $0 \mathrm{mV}$ for $1 \mathrm{sec}$. Both protocols lead to the induction of maximal DSI (Glitsch et al., 2000). DSI was induced repetitively in each experiment, with a typical inter-DSI interval of $3 \mathrm{~min}$.

The analysis of mIPSCs and spontaneous IPSCs (sIPSCs) was performed using homemade routines written in Igor Pro (Wavemetrics, Lake Oswego, OR) as previously described (Diana et al., 2002). After automatic event detection, time was divided into 2-sec-long bins; frequency, average amplitude, and cumulative amplitude (i.e., the sum of all the amplitudes) were calculated from the synaptic currents falling into corresponding bins. The $60 \mathrm{sec}$ preceding DSIs were considered as a control period; the reduction over the first $10 \mathrm{sec}$ in DSI with respect to the control was evaluated by averaging the first five bins after DSI induction. Separate DSI trials were then pooled together.

The analysis of the DSI of eIPSCs was performed as follows. For each DSI trial, the eIPSCs falling into the $60 \mathrm{sec}$ time interval (for 0.5 and 0.33 $\mathrm{Hz}$ stimulation rates) or into the $90 \mathrm{sec}$ time interval (when stimulating at $0.2 \mathrm{~Hz}$ ) before DSI were considered control periods. Maximal DSI was calculated as the percentage of inhibition corresponding to the ratio between the average amplitude of the eIPSCs in the first $10 \mathrm{sec}$ after the induction protocol $(n=3$ eIPSCs at $0.2 \mathrm{~Hz} ; n=4$ at $0.33 \mathrm{~Hz}$; and $n=5$ at $0.5 \mathrm{~Hz}$ ) and the average amplitude in control. The DSI value for a single experiment was calculated as the average value of all the DSI trials.

The paired pulse ratio was measured as the ratio between the average amplitude of the second eIPSC over that of the first for groups of paired evoked currents. The rise time was defined as the period required for eIPSCs to increase from 20 to $80 \%$ of their maximum amplitude, whereas the time between the peak of the presynaptic action potential and the $20 \%$ point on the rising phase of the postsynaptic currents was considered the synaptic latency. The decay time constant was calculated by fitting the eIPSC with a monoexponential function starting at the point of maximal amplitude.

For rise time, latency, decay time constant, failure rate, and paired pulse ratio measurements, the average values from the eIPSCs falling in the first $35 \mathrm{sec}$ after DSI ( $n=8$ eIPSCs at $0.2 \mathrm{~Hz} ; n=12$ at $0.33 \mathrm{~Hz}$; and $n=18$ at $0.5 \mathrm{~Hz}$ ) represented the test period, as opposed to the control period, which was set as for the quantification of DSI; values for a single experiment were obtained by pooling together the averages from each DSI trial in each condition. Thus, figures denoting a single experiment were averages from multiple (typically 5-10) DSI trials.

To study the behavior of the variance-to-mean ratio $(\mathrm{v} / \mathrm{m})$ for the eIPSCs during DSI, only experiments in which the presynaptic stimulation rate was $0.2 \mathrm{~Hz}$ were considered; shorter periods were selected so that stationarity could be assumed. On the basis of the time course of DSI represented in Figure 4C, eIPSCs were divided into groups of three. Both the control and test periods were divided into such triplets, for which average amplitudes $(m)$, variances $(v)$, and $v / m$ were calculated. For each DSI trial, $\mathrm{v} / \mathrm{m}$ values were normalized using the average $\mathrm{v} / \mathrm{m}$ from the triplets in the control period. Finally, the values for the various DSI trials of an experiment were averaged to give a single contribution per DSI triplet and per paired recording to the final statistics.

Results are given as means \pm SEM. Statistical comparisons were made using Wilcoxon's signed rank test for paired samples and the MannWhitney $U$ test. Comparisons were either inside an individual experiment (in which case $n$ designated the number of DSI trials) or between pooled experiments (in which case $n$ represented the number of experiments in each condition). Correlation was evaluated by computing the Kendall rank correlation coefficient. Statistical significance was set at $p=0.05$.

Morphological reconstruction. At the end of a perforated patch recording, the cell body of the presynaptic interneurons typically remained intact after withdrawal of the recording pipette. We took advantage of this fact, and we recovered the interneuron morphology with a fast and noninvasive technique based on the lipophilic dye DiI, which gave reliable results and allowed the visualization of the plausible contact areas with a confocal microscope (see Fig. 2C). During paired recordings, Purkinje cells were filled through the recording pipette with Lucifer yellow (0.3\%; Sigma). As for basket and stellate cells, after recording, a new pipette was filled with DiI (Molecular Probes, Eugene, OR) dissolved in methylene chloride (0.5\%; Sigma). A dye crystal typically formed at its 
tip; the pipette was then placed in contact with the cell soma and rapidly removed to permit the deposition of the crystal without damaging the cellular structure. The slices were then fixed for $48 \mathrm{hr}$ at $4^{\circ} \mathrm{C}$ in $4 \%$ paraformaldehyde (Sigma) and $0.15 \mathrm{~m}$ phosphate buffered solution (PB) for fixation and left in $\mathrm{PB}$ for a further $48 \mathrm{hr}$ at the same temperature to permit the full diffusion of the dye on the cellular membrane. Finally, the slices were mounted on glass slides in Dako (Carpinteria, CA) fluorescence mounting medium. Series of images at incremental $z$-axis positions were taken and superimposed using a Zeiss LSM 410 confocal microscope equipped with two different lasers at 488 and $543 \mathrm{~nm}$ wavelengths for Lucifer yellow and Dil, respectively.

\section{Results}

\section{DSI of TTX-sensitive and -insensitive IPSCs}

The form of retrograde inhibition that has been designated DSI in previous publications is actually the superimposition of multiple processes so that, as it will appear below, the quantification of the associated peak percentage reduction of synaptic strength strictly depends on the experimental conditions. In the following, we introduce different terms to define the extent of reduction for different classes of experiments. Namely, we call DSI the maximal inhibition of the collective sIPSCs recorded in one cell, DSI $_{m}$ the maximal inhibition of mIPSCs, and DSI $_{e}$ the inhibition of eIPSCs obtained from paired recording experiments. The main goal of the present work is to measure these different forms of DSI and to understand their mutual relations, as well as their link with the reduction in presynaptic action potential frequency $\left(\mathrm{DSI}_{\mathrm{AP}}\right)$ recently described by Kreitzer et al. (2002).

We first performed a series of experiments to analyze the time course of DSI and to characterize the relative contributions of IPSC frequency and average amplitude inhibition to $\mathrm{DSI}_{\mathrm{s}}$ and DSI $_{m}$. An important goal of these experiments was to allow a quantitative comparison in the same experimental conditions with the results of paired recordings to be described below. These results expand and complete previous reports on $\mathrm{DSI}_{\mathrm{s}}$ and $\mathrm{DSI}_{\mathrm{m}}$ in this preparation (Llano et al., 1991; Glitsch et al., 1996).

Figure $1 A$ illustrates the modulation of sIPSCs in the absence of TTX; whereas the top trace displays a typical DSI protocol from one such experiment, the middle graph shows the time course of the cumulative amplitude obtained from averaging normalized results across experiments, yielding a mean peak reduction $\left(\mathrm{DSI}_{\mathrm{s}}\right)$ of $64.2 \pm 8.2 \%(n=14)$; the half-time of recovery was $37.9 \pm 3.8 \mathrm{sec}$. Reductions in the frequency and in the average amplitude of sIPSCs contribute in equal proportions to the decrease of the cumulative amplitude: they amount to $39.9 \pm 4.7$ and $41.3 \pm 4.2 \%$, respectively. The bottom graph of Figure $1 \mathrm{~A}$ shows that the time course of recovery of the normalized average amplitude is very similar to that of the cumulative amplitude. The same held true for the frequency (data not shown).

Results of similar experiments performed in the presence of TTX $(200-500 \mathrm{~nm})$ are presented in Figure $1 B$. The average reduction of the cumulative amplitude $\left(\mathrm{DSI}_{\mathrm{m}}\right)$ was $43.3 \pm 3.5 \%$ $(n=13)$; this value is significantly smaller than that obtained in the absence of TTX ( $p<0.01$; Mann-Whitney $U$ test $)$. In agreement with earlier reports (Llano et al., 1991; Glitsch et al., 1996), the entire effect could now be accounted for by a change in event frequency (amounting to $45.2 \pm 3.0 \%$; data not shown), whereas the mean amplitude was unchanged (slight increase by $5.7 \pm$ $4.9 \%$ compared with control values; Fig. $1 B$, bottom graph). Here we note in addition that the half-recovery time measured in TTX was $35.1 \pm 3.4 \mathrm{sec}$, not different from that observed for TTX-dependent sIPSCs ( $p \gg 0.1$; Mann-Whitney $U$ test). Thus, even though the extent of DSI ${ }_{s}$ and DSI ${ }_{m}$ differed, the time course of the effect was the same in the two cases.
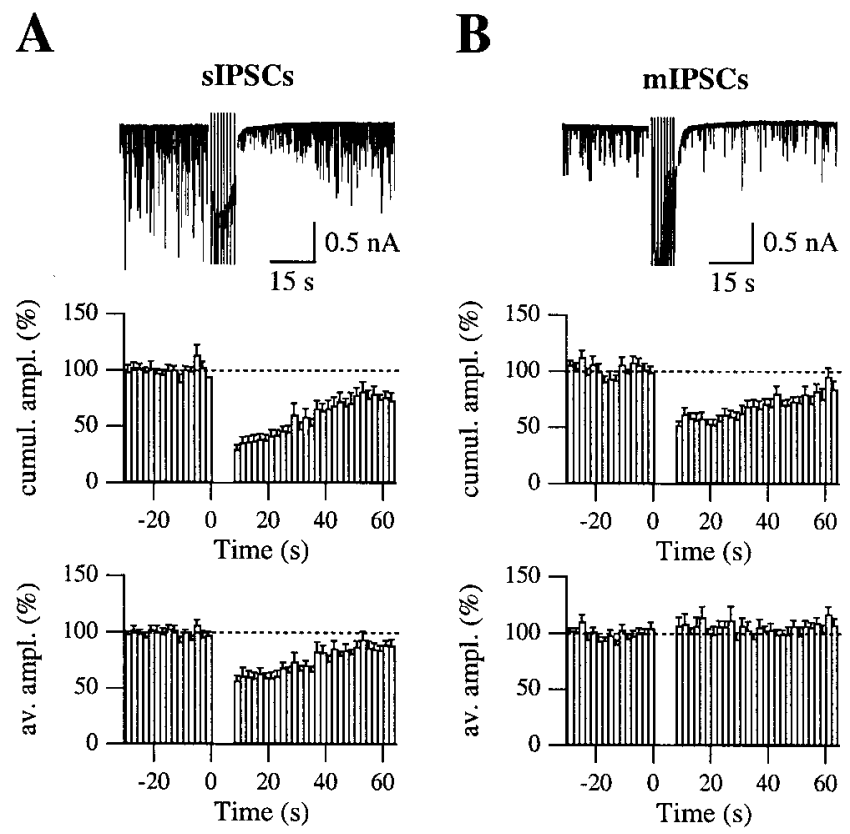

Figure 1. $\quad D S I_{s}$ and $D S I_{m}$. Illustrated are the effects of postsynaptic depolarization on the spontaneous synaptic activity in Purkinje cells as recorded in the presence of blockers of glutamatergic synaptic currents. $A$, Action potential-dependent and -independent synaptic currents both contribute to the overall population of sIPSCS. The top trace shows a typical DSI protocol. After a control period, the Purkinje cell is depolarized 8 times for $100 \mathrm{msec}$ to $0 \mathrm{mV}$, at $1 \mathrm{~Hz}$; the trace shows the consequent dramatic inhibition of sIPSCs and, thereafter, their recovery phase over $60 \mathrm{sec}$. In this cell, four such protocols were averaged, yielding $79.6 \pm 0.5 \%$ inhibition in the sIPSC cumulative amplitude (cumul. ampl.), calculated over the first 10 sec after the end of the pulse train. Decreases in the frequency and in the average amplitude (av. ampl.) contributed in equal measure to this reduction: $53.6 \pm 4.3$ and $55.2 \pm 4.3 \%$, respectively. The two bottom graphs show the time course of the DSI of cumulative and average amplitudes for $n=14$ experiments performed with this protocol; as for the single case depicted in $A$, frequency (data not shown) and average amplitude are equally inhibited during DSI and recover back to control levels with the same time course. B, DSI of mIPSCs, recorded in the presence of $200-500 \mathrm{~nm} \mathrm{TTX.}$ In the experiment shown, the inhibition of the mIPSC cumulative amplitude was $64.7 \pm 4.0 \%$ over four DSI trials. In contrast to the sIPSC results, the reduction of mIPSC frequency totally accounts for the DSI of the cumulative amplitude; the bottom graph shows that the average amplitude of $\mathrm{mIPSC}$ remains totally unaffected by the induction protocol (average graphs from 13 cells).

\section{Rationale for studying DSI in paired recordings}

The resting frequencies of sIPCSs and mIPSCs in the two separate series of experiments used for the analysis of Figure 1 were $11.1 \pm$ $1.4 \mathrm{~Hz}$ (range, 3.4-20.2 Hz; $n=14$ ) and $8.2 \pm 1.4 \mathrm{~Hz}$ (range, $2.7-17.7 \mathrm{~Hz} ; n=15)$, respectively; corresponding cumulated amplitude values were 1808 and $986 \mathrm{pA} / \mathrm{sec}$. It is most likely that sIPSCs include action potential-independent IPSCs, which have very similar properties to those of mIPSCs recorded in TTX. According to the above values, the contribution of action potential-independent IPSCs to sIPSCs was very substantial. However, the proportion that can be derived from these data is not accurate given the very large scatter of the results obtained with different cells. More reliable figures were obtained in a series of experiments performed for another study in which sIPSCs were directly compared in individual cells with and without TTX. These results indicate that action potential-independent IPSCs contribute $47 \%$ of sIPSCs and that they account for $21 \%$ of their cumulative amplitude (J. Gonzalez, A. Marty, and I. Llano, unpublished results). Thus, the share of these IPSCs in the overall inhibitory synaptic input of Purkinje cells is far from negligible.

The finding that one component of sIPSCs (the action 
potential-independent IPSCs) was less reduced than the overall population during DSI therefore implies that the other component (action potential-evoked IPSCs) was more strongly inhibited than the mean sIPSCs. This strong inhibition could involve a reduction of the frequency of generation of action potentials by the presynaptic cell, of the probability of action potential transmission along the axon, or of the probability of neurotransmitter release. To sort out these possibilities and to find out the exact amount of DSI applying to action potential-evoked currents, paired recordings were performed between presynaptic interneurons and postsynaptic Purkinje cells. Vincent and Marty (1996) found an inverse correlation between the strength of this synaptic connection and the depth of the location of presynaptic interneurons in the molecular layer; for this reason, our paired recording experiments were primarily performed using presynaptic cells located in the lower two-thirds of the molecular layer (basket cells and proximal stellate cells).

\section{Rundown of eIPSCs can be prevented by using presynaptic perforated patch recording}

We first performed whole-cell recordings of the presynaptic neurons to control the ionic composition and the firing rate of the presynaptic cell. Although DSI could be readily obtained under these conditions (data not shown), the analysis of the results was severely restricted by the fact that an irreversible decline ("rundown") of the synaptic strength occurred within 10-20 min of presynaptic whole-cell recording (Fig. 2A) (presynaptic washout at this synapse was previously mentioned by Vincent and Marty, 1996). However, if the presynaptic recording was performed using the perforated patch technique, data could be recorded over $\geq 1 \mathrm{hr}$ without any significant rundown (Fig. $2 \mathrm{~B}$ ). These results suggest that a diffusible, water-soluble substance is responsible for the washout observed with conventional presynaptic wholecell recording. For this reason, the remaining part of this paper presents results obtained with the perforated patch technique. In a fraction of the experiments, the morphology of the presynaptic and postsynaptic cells was recovered using a combination of presynaptic staining with DiI and postsynaptic staining with Lucifer yellow (see Materials and Methods), as illustrated in Figure 2C. As exemplified in this figure, connected pairs typically displayed extensive or numerous areas of potential contacts, or both, suggesting the presence of multiple release sites.

\section{A DSI experiment using paired recording}

A typical DSI experiment performed under these conditions is illustrated in Figure 3. In the control period, voltage pulses to 0 $\mathrm{mV}$ were applied presynaptically at $0.2 \mathrm{~Hz}$, giving rise to action currents, which reflected the onset of axonal action potentials and to eIPSCs in the Purkinje cell (Fig. $3 A$ ). The corresponding presynaptic $\mathrm{Ca}^{2+}$ transients are undistinguishible from those obtained with presynaptic current-clamp stimulations (Tan and Llano, 1999). Amplitudes of eIPSCs were large: the average was $1.00 \pm 0.25 \mathrm{nA}(n=22$ pairs with a postsynaptic chloride-based

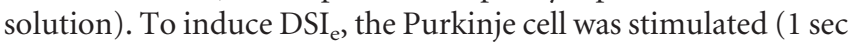
pulse to $0 \mathrm{mV}$ ); when resuming presynaptic stimulations, presynaptic signals were unchanged (Fig. $3 A$, inset traces), but eIPSC amplitudes were markedly reduced (Fig. $3 A$, bottom right traces), reflecting DSI $_{\mathrm{e}}$. Figure $3 A$, bottom graph, depicts the time course for this DSI trial. Here, circles indicate eIPSC amplitudes during control and post-DSI periods, whereas dots show results obtained in the $90 \mathrm{sec}$ period after Purkinje cell depolarization (given at $t=0)$.

Figure $3 B$ shows the time course of the eIPSC amplitudes for
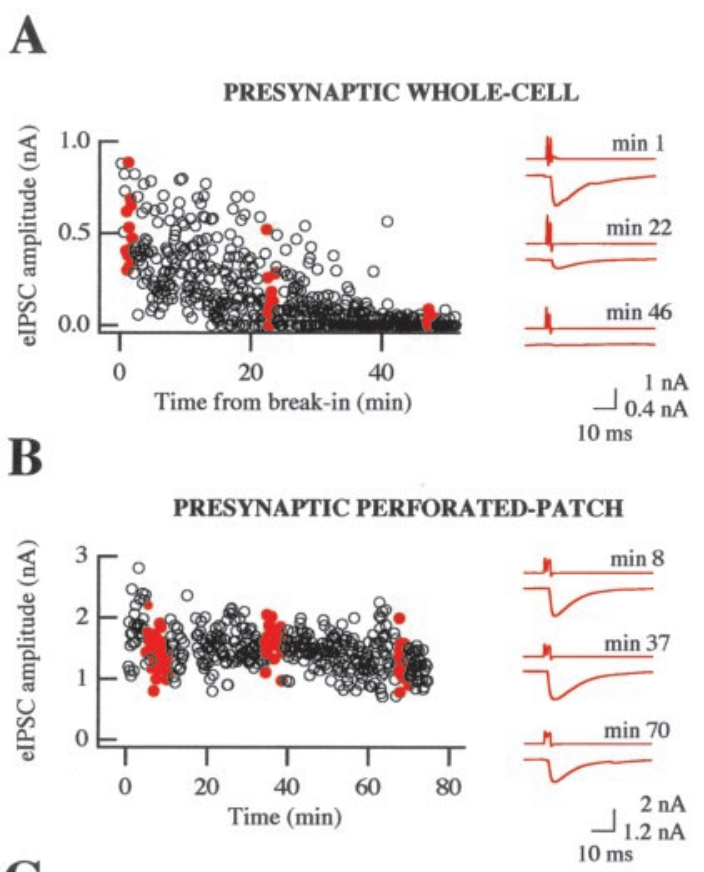

C

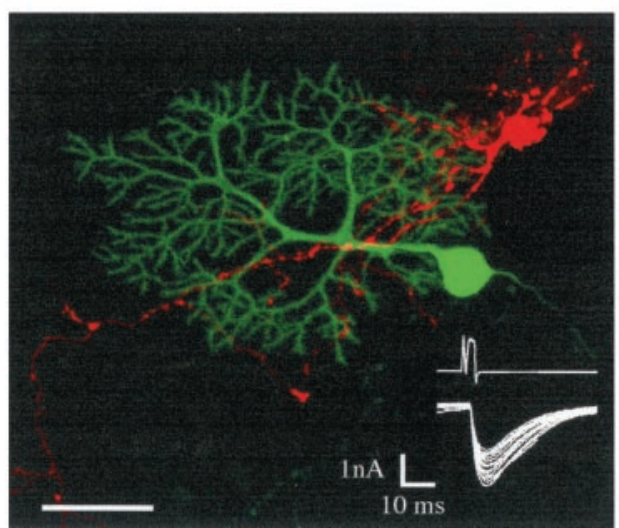

Figure 2. Rundown of elPSCs is prevented by presynaptic perforated patch recording. $A$, Typical paired recording in which the presynaptic interneuron was whole-cell voltage-clamped with a $\mathrm{K}^{+}$-gluconate-based solution. The amplitude of eIPSCs slowly decreased with time of presynaptic dialysis. The red traces show the average presynaptic and postsynaptic currents; corresponding amplitudes are indicated by the filled red symbols in the time plot on the left. The presynaptic interneuron was stimulated at $0.2 \mathrm{~Hz}$. Time 0 was set at the moment of the rupture of the presynaptic seal. $B$, Results obtained with presynaptic perforated patch recording. In this case, time 0 was taken when presynaptic access was sufficient to allow the triggering of an axonal action potential with a depolarizing somatic voltage pulse. C, Morphology of a connected interneuron (a low stellate cell in this case, shown in red, Dil membrane staining)-Purkinje cell (green, Lucifer yellow intracellular staining) pair. Fifty images taken at incremental z-axis coordinates have been superimposed; note that the main presynaptic axonal shaft and some collateral branches appear to contact the dendrites of the postsynaptic Purkinje cell on several distinct locations, indicated by yellow spots. The inset represents 15 superimposed elPSCs from this paired recording, with the corresponding presynaptic currents. Scale bar, $40 \mu \mathrm{m}$.

the same experiment, including nine successive DSI $_{e}$ trials; dot clusters represent $90 \mathrm{sec}$ periods corresponding to DSI . It is immediately apparent that DSI $_{e}$ could be reliably induced throughout the experiment. The box indicates the DSI $_{e}$ trial depicted in Figure $3 A$. Taking advantage of the stability of the amplitude of eIPSCs in the control and DSI $_{e}$ periods, pooled amplitude histograms were calculated in the control (open bars) and in the first $35 \mathrm{sec}$ after DSI induction (corresponding to the first eight eIPSCs; the extent of DSI $\mathrm{e}_{\mathrm{e}}$ calculated over this time window was 
A
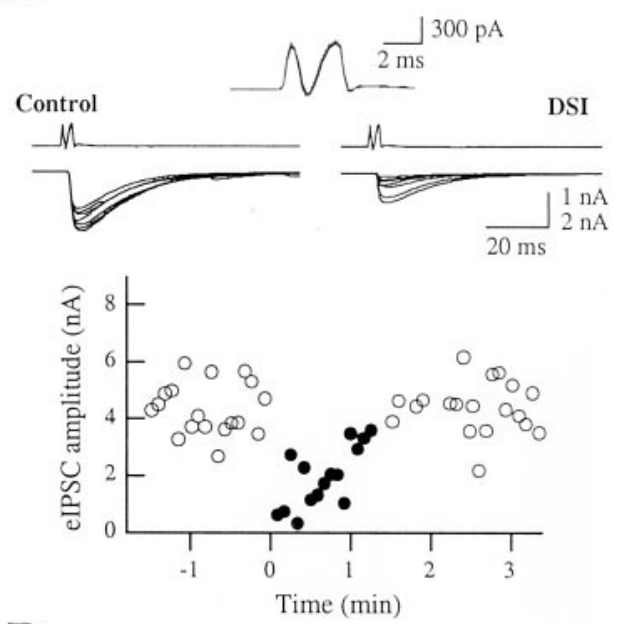

B

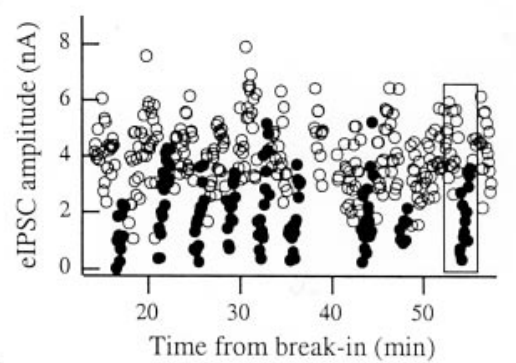

C

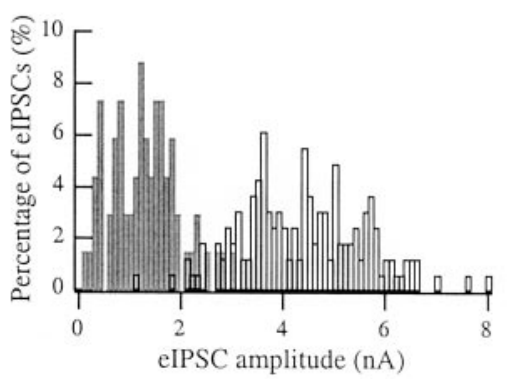

Figure 3. DSI experiment in paired recordings. A, DSI was induced by depolarizing the Purkinje cell once to $0 \mathrm{mV}$ for $1 \mathrm{sec}$. Left, Seven superimposed presynaptic and postynaptic traces during the control period. Right, First seven eIPSCs after the induction protocol. Inset, Average presynaptic currents were identical for the control (black) and test (gray) periods. Bottom graph, Time course of eIPSC amplitudes for this DSI trial. Each symbol is the amplitude of an individual evoked response; circles represent control amplitudes, whereas dots represent the first $90 \mathrm{sec}$ during DSI. The presynaptic stimulation rate was $0.2 \mathrm{~Hz}$. B, Time course of the experiment. Each series of dots represents $90 \mathrm{sec}$ after a DSI induction protocol. The box indicates the DSI trial illustrated in A. Note that DSI could be reliably induced over tens of minutes. C, Histograms of control eIPSC amplitudes (open bars) and test eIPSCs (gray) pooled from the DSI trials shown in $B$; the 90 sec preceding DSI were chosen for each depolarization as a control (corresponding to $18 \mathrm{eIPSCs}$ at $0.2 \mathrm{~Hz}$ ) and the following $40 \mathrm{sec}$ as a test (8 elPSCs); notice the clear difference between the two distributions. Using these time intervals, DSI amounted to $69.7 \%$. In this particular experiment, no failures were detected either in control or during DSI.

69.7\%) for all the DSI $_{e}$ trials performed in this experiment. Even though both histograms are quite broad, reflecting a substantial range of amplitude fluctuations in each condition, there was very little overlap between the two distributions. This excludes the possibility that $\mathrm{DSI}_{\mathrm{e}}$ would work simply by stopping the propagation of the action potential along the main axon, because the distribution of nonfailure events would then be the same during DSI $_{e}$ and in the control. Nevertheless, these data would still be compatible with a blocking action in action collaterals, as discussed below.

Reliability of induction and time course of DSI $_{e}$

Pooling together the results of several DSI trials, as has been done in Figure $3 C$, requires that the properties of $\mathrm{DSI}_{\mathrm{e}}$ remain stable during the entire duration of the recording. To test this assumption, we plotted the mean of all $\mathrm{DSI}_{\mathrm{e}}$ values obtained $(n=17$ pairs) as a function of the time in the whole-cell configuration for

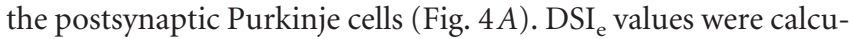
lated over $35 \mathrm{sec}$ periods after Purkinje cell depolarization in this analysis. The results indicate that $\mathrm{DSI}_{\mathrm{e}}$ does not decline at least up to $80 \mathrm{~min}$ after establishing the whole-cell configuration. As an example, the values of DSI between 5 and $10 \mathrm{~min}(55.8 \pm 7.2 \%$; $n=11$ DSI trials) and between 50 and $55 \min (62.0 \pm 6.2 \%$; $n=$ 13 DSI trials) after breaking into Purkinje cells are not statistically different ( $p>0.05$, Mann-Whitney $U$ test).

In the hippocampus, DSI $_{e}$ results are extremely variable in paired recordings: some pairs have essentially $100 \% \mathrm{DSI}_{\mathrm{e}}$, whereas others have a negligible DSI level (Wilson et al., 2001); this is likely to reflect the different sensitivity to cannabinoids of distinct interneurons subtypes (Katona et al., 1999; Tsou et al., 1999). In sharp contrast to this situation, we find that, in our preparation, the distribution of $\mathrm{DSI}_{\mathrm{e}}$ values is rather homogeneous, with values from most experiments centered at $\sim 70 \%$ (Fig. $4 B$ ).

Figure $4 C$ shows the average time course of $\mathrm{DSI}_{\mathrm{e}}$ obtained from 14 paired recordings in which the presynaptic stimulation

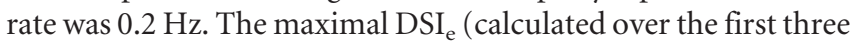
eIPSCs after the DSI induction protocol) was $68.8 \pm 4.7 \%$, with values ranging from 23.2 to $94.4 \%$. It is interesting to note that a significantly higher value $(88.8 \pm 3.7 \%)$ was recently found in another series of experiments using paired recordings (Diana et al., 2002). The discrepancy with the present study is likely to be related to the different intracellular solutions used in the Purkinje cells (low $\mathrm{Cl}^{-}$concentration in the previous study vs isotonic $\mathrm{Cl}^{-}$in the present work).

A close examination of the time course of $\mathrm{DSI}_{e}$ recovery in Figure 4 reveals three different phases. There was first an almost stable period, lasting $20 \mathrm{sec}$ and corresponding to the first four trials after induction. This was followed by a rather rapid decline in the period 20-60 sec after the depolarization. The halfrecovery occurred at $42.1 \pm 2.8 \mathrm{sec}(n=11)$, not significantly different from the values obtained for sIPSCs $(37.9 \mathrm{sec}$ ) and mIPSCs (35.1 sec; see above; $p>0.05$ in both cases, MannWhitney $U$ test). A small residual inhibition remained at $60-80$ $\mathrm{sec}$, indicating the presence of a secondary component with slower kinetics. A similar component is in fact apparent in Figure $1, A$ and $B$. Overall, the kinetics of DSI recovery appeared to be the same independently of whether sIPSCs, mIPSCs, or eIPSCs were measured.

The difference between $\operatorname{DSI}_{e}(68.8 \%)$ and $\operatorname{DSI}_{s}(64.2 \%)$ is not statistically significant ( $p>0.10$, Mann-Whitney $U$ test). This may seem paradoxical because we argued earlier that the latter include mIPSCs, which are comparatively little affected. However, recent results indicate that the firing rate of interneurons decreases during DSI (Kreitzer et al., 2002). This effect does not appear in our paired recording experiments, in which the presynaptic stimulus was suprathreshold and reliably gave rise to somatically recorded action currents even during DSI periods. Therefore, whereas the actual contribution of action potential-evoked sIPSCs originating at one interneuron $\rightarrow$ Purkinje synapse is given by the product of the presynaptic firing rate and of the 
A

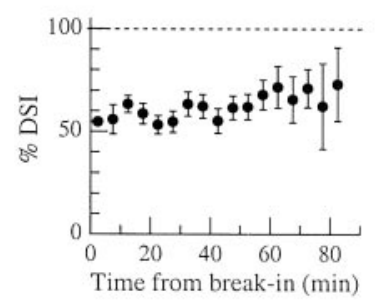

B

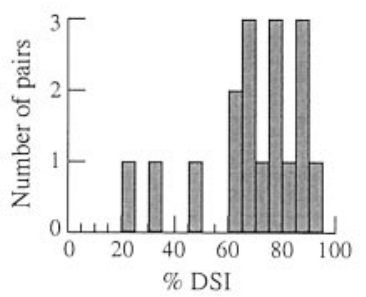

C

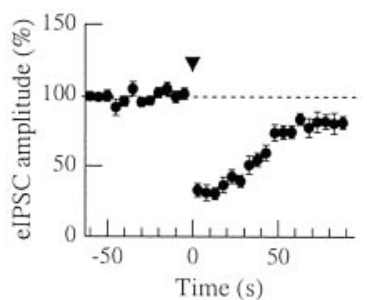

Figure 4. Characterization of DSI $\mathrm{e}$ in paired recordings. A, Peak DSI values (calculated using the first 8 elPSCs during DSI periods) as a function of the duration of postsynaptic whole-cell recording. Notice the reliability of DSI induction over the long postsynaptic recording times. $B$, Distribution of peak DSI $\mathrm{e}_{\mathrm{e}}$ alues for 17 paired recordings. The distribution is uniform; most values are centered around a mean of $\sim 70 \%$. This is consistent with a homogeneous distribution of CB1Rs on basket and lower stellate cells, as suggested in a previous publication (Diana et al., 2002). C, Normalized time course of DSI for 14 paired recordings in which presynaptic interneurons were stimulated every $5 \mathrm{sec}$. This time course is not significantly different from those of DSI $\mathrm{m}_{\mathrm{m}}$ and of DSI $\mathrm{s}_{\mathrm{s}}$. Note the residual $\sim 10 \% \mathrm{DSI}_{\mathrm{e}}$ at $70-90$ sec after stimulation, indicating a slower secondary recovery phase.

eIPSC amplitude, the DSI $_{e}$ value appearing in Figure 4 includes only the latter component. Incorporating the reduction in firing rate results in a larger DSI value, which compensates for the lower DSI of mIPSCs (see Appendix).

\section{Increase in the failure rate during DSI}

Previous experiments using extracellular stimulation suggested an increase in the failure rate during DSI (Vincent et al., 1992; Alger et al., 1996). However, a quantitative interpretation of these experiments is difficult because of uncertainties on the number of stimulated presynaptic cells and on the exact pattern of presynaptic action potentials elicited by each stimulation pulse. Also, the earlier experiments used "minimal stimulation"

A

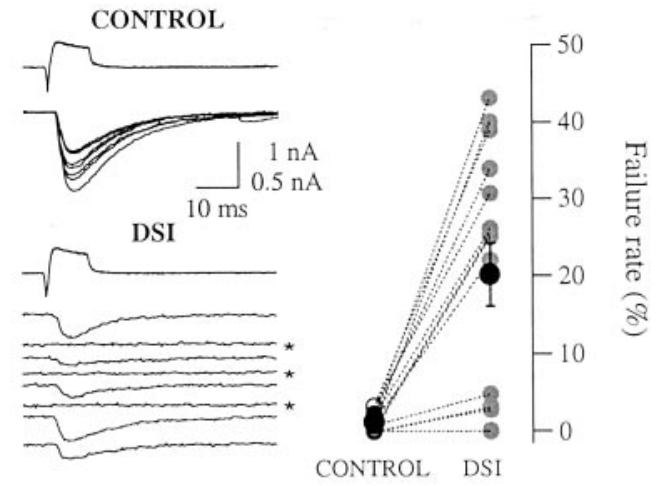

B
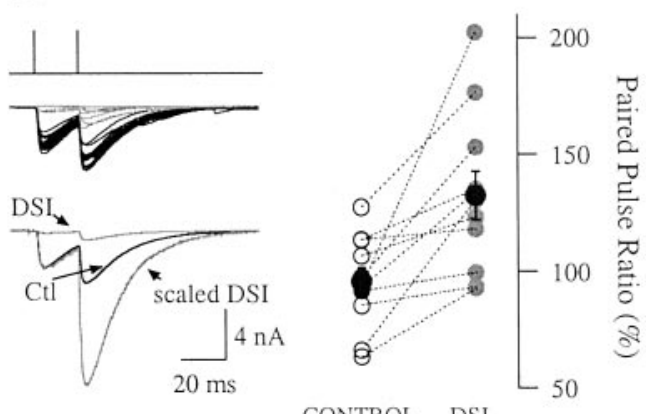

CONTROL DSI

Figure 5. Failure rate and PPR increase during $D S \mathrm{e}_{\mathrm{e}^{-}} A$, Failure rate and DSI. Top left plot, Control presynaptic and postsynaptic currents (8 superimposed traces). Bottom left plot, Series of eight consecutive traces during DSI showing three transmission failures (asterisks indicate individual postsynaptic traces have been separated to better illustrate failures), whereas none occurred in the control. In this experiment, the failure rate increased from $0.4 \pm 0.4$ to $26.2 \pm$ $3.6 \%(n=14$ DSI trials $)$, whereas DSI amounted to $73.1 \pm 1.75 \%$. Right, Dashed lines connect pairs of points representing the failure rate in the control (open symbols) and test (closed symbols) periods for individual experiments. Mean failure rates from the 15 considered pairs are shown by larger black symbols. The failure rate increased in each experiment with the exception of two, in which none was present either in control or during DSI. B, PPR and DSI. Presynaptic interneurons were stimulated twice at $20 \mathrm{msec}$ intervals at $0.2 \mathrm{~Hz}$. Left, Control (Ctl; black) and DSI (gray) traces (top series, superimposed individual traces; bottom series, their averages). The scaled DSI trace was calculated to match the amplitude of the first elPSC in the control. In this experiment, the PPR increased from $97.8 \pm 3.7$ to $155.8 \pm 19.8 \%$. DSI $\mathrm{e}$ values were $85.1 \pm 2.1$ and $78.7 \pm 2.0 \%$ for the first and second elPSCs, respectively ( $n=8$ DSI trials). Right, Mean PPR results from 11 experiments. The PPR increases in each case. conditions, with mean currents on the order of $\leq 200 \mathrm{pA}$; although DSI seemed to eliminate well defined, presumably multiquantal components, suggesting propagation failures (Alger et al., 1996), it could not be excluded that the failures were attributable to a homogeneous reduction in release probability. We hoped to shed light on this issue by examining DSI-induced failures in our paired recordings, which started off with very large eIPSC amplitudes.

An earlier study showed that the probability of release of interneuron $\rightarrow$ Purkinje synapses is age-related and that this probability is at its maximum for this preparation at the age covered in this study (postnatal days 11-15; Pouzat and Hestrin, 1997). In agreement with these findings and with the very large control IPSC amplitude, we found a very low failure rate in control conditions, amounting to $1.2 \pm 0.3 \%$ (range, $0-3.2 \% ; n=15$ pairs). We compared next the failure rate in control and in DSI periods. To increase the number of sample data analyzed, for each DSI trial the failure rate was calculated for the first eight eIPSCs after the Purkinje cell depolarization. An increase in failure rate was readily apparent in all experiments, except for 2 pairs, which did not display any failure either in control or in DSI conditions. An example of a DSI $I_{e}$ trial is shown in Figure 5A, left traces; three of eight presynaptic stimulations induced postsynaptic failures (postsynaptic traces indicated by an asterisk), whereas no failures were observed in the control. Interestingly, the eight presynaptic traces during DSI are exactly superimposed, and they are identical to the control traces; these results do not indicate any association of failures with modifications of presynaptic somatic signals.

When averaging across experiments, the failure rate increased from $1.2 \pm 0.3$ to $20.2 \pm 4.1 \%(n=15 ; p \ll 0.05$, Wilcoxon's test; Fig. 5A, right graph).

\section{Paired pulse ratio and DSI}

A classical method to investigate the participation of presynaptic mechanisms in synaptic plasticity is to analyze the paired pulse ratio (PPR) for two closely successive stimulations. In the CA1 region of the hippocampus, there are contradictory reports about the relationship between PPR and DSI. Alger et al. (1996) and Varma et al. (2002) reported that DSI was not associated with any systematic modification in the PPR. This result was interpreted as indicating that the inhibition of eIPSCs was primarily attributable to propagation failures, whereas invading action potentials would release GABA essentially as in control conditions. In con- 
trast, another group reported an increase in the PPR during DSI, as expected for a graded modulation of the probability of transmitter release in presynaptic terminals (Wilson and Nicoll, 2001). The link between DSI and PPR has been examined in the cerebellum by studying currents evoked by extracellular stimulation protocols (Yoshida et al., 2002); given the recent report by Kreitzer et al. (2002) on the inhibition of presynaptic firing during DSI, we considered it important to readdress this question using paired recordings in which the presynaptic spike rate is under precise experimental control.

To measure the PPR, two consecutive presynaptic depolarizations were given with an interval of $20 \mathrm{msec}$ at $0.2 \mathrm{~Hz}$; as before, eight paired stimulations were analyzed during the DSI period. The PPR was calculated from averaged results rather than from individual sweeps to avoid introducing a statistical bias in the analysis of the results (Kim and Alger, 2001). In control conditions, the PPR was 95.6 $\pm 5.9 \%(n=11)$. This is larger than the values reported earlier at this age [in rats (Pouzat and Hestrin, 1997) and in mice (Caillard et al., 2000)]. The difference could stem from the use of presynaptic perforated patch recording in the present study versus whole-cell recording in the earlier work and from the effects on transmission attributable to the dialysis of the presynaptic intracellular milieu by the latter technique.

In the present experiments, the paired pulse ratio was clearly increased during DSI (Fig. 5B). This effect was seen in 11 of 11 investigated pairs. In the example shown in Figure $5 B$, left, the PPR value increased from $97.8 \pm 3.7$ to $155.8 \pm 19.8 \%(n=8$ DSI trials). When averaging across experiments, the paired pulse ratio grew from $95.6 \pm 5.9 \%$ in the control to $132.6 \pm 10.3 \%$ during DSI ( $p \ll 0.05$, Wilcoxon's test; $n=11$; Fig. $5 B$, right). These results do not exclude propagation failures, but they show that propagation failures, if present, cannot be the only mechanism underlying $\mathrm{DSI}_{\mathrm{e}}$. Rather, cerebellar $\mathrm{DSI}_{\mathrm{e}}$ must involve a reduction of release probability once a presynaptic action potential effectively reaches synaptic terminals.

\section{Kinetic parameters of eIPSCs}

Few studies have been concerned with eIPSC kinetics during DSI, apart from early reports using extracellular stimulation, which indicated an increase in the time course of decay (Vincent et al., 1992) and no change in latency (Alger et al., 1996). Even though the above results and the existing literature clearly indicate that DSI must involve a strong presynaptic component, the possibility of additional postsynaptic components (e.g., involving changes in GABA receptor phosphorylation) cannot be excluded. Such effects could become manifest as kinetic changes of the eIPSCs. Presynaptic effects can also lead to kinetic alterations such as latency changes (for review, see Lin and Faber, 2002). Therefore, effects of DSI on eIPSC kinetics were analyzed in paired recordings. In control, the $20-80 \%$ rise time was $1.47 \pm 0.20 \mathrm{msec}$ (range, $0.79-2.66 \mathrm{msec}$ ). In the test period (eight first stimulations during each DSI $_{\mathrm{e}}$ trial), the corresponding value was $1.57 \pm$ $0.22 \mathrm{msec}(n=13$; no significant change; $p>0.05$, Wilcoxon's test). In conformity to previous findings (Vincent et al., 1992), the decay phase of the eIPSCs could be well described with a monoexponential fit; the average decay time constant was $12.1 \pm$ $0.9 \mathrm{msec}$ (range, $6.4-15.6 \mathrm{msec}$ ) in control conditions. However, whereas a $32 \%$ increase was associated with DSI in the previous experiments, we found a mean value of $12.7 \pm 1.2 \mathrm{msec}$ during $\mathrm{DSI}_{\mathrm{e}}$ (range, 8.6-19.9 msec; $n=10 ; p>0.05$, Wilcoxon's test), not statistically different from the control.

Although the exact reason for the discrepancy with the earlier results by Vincent et al. (1992) is unclear, we take the present results as indicating that the postsynaptic calcium rise does not lead to any significant change in the state of the postsynaptic GABA receptors.

Next we evaluated the latency by measuring the interval between the peak of the presynaptic action current and the point in time when eIPSCs reached $20 \%$ of their maximal amplitude. The latency was $1.99 \pm 0.18 \mathrm{msec}$ in control runs (range, 1.39-2.85 $\mathrm{msec}$ ) and did not change significantly during DSI $\mathrm{e}_{\mathrm{e}}$, with a mean of $2.04 \pm 0.17 \mathrm{msec}$ (range, $1.15-2.85 \mathrm{msec} ; n=11 ; p>0.05$, Wilcoxon's test). These results agree with a previous study by Alger et al. (1996) and indicate that (at least with normal presynaptic ionic conditions; see results of Fig. 8 below) DSI $_{e}$ does not involve any detectable change in the timing of GABA release and in the action potential propagation speed.

\section{Variance analysis}

It was reported earlier that the amplitudes of eIPSCs obtained at interneuron $\rightarrow$ Purkinje cell synapses are highly variable. Part of this variability stems from the large size of mIPSCs, but, in addition, it was proposed that the presynaptic calcium signal varies from one trial to the next (Vincent and Marty, 1996). The question therefore arises of whether trial-to-trial variations are modified during DSI.

Our results confirmed the earlier finding of very large fluctuations of eIPSC amplitudes in the control. The $\mathrm{v} / \mathrm{m}$ averaged $80.2 \pm 12.4 \mathrm{pA}(n=22)$. This ratio is related to the quantal size in a model-specific way. For instance, if one assumes a series of release sites with an exponential distribution of quantal sizes having a mean value $q$ and a homogeneous release probability $p$, the $\mathrm{v} / \mathrm{m}$ value (Vincent and Marty, 1996) is given by:

$$
v / m=2 q(1-p)
$$

To determine the variance of eIPSC amplitudes during DSI and to minimize errors linked to the evolution of the mean value with time during the DSI period, results were grouped in periods of three consecutive presynaptic stimulations, called triplets hereafter (see Materials and Methods). Variance-to-mean ratios were determined for two consecutive triplets during DSI and compared with pre-DSI periods. A representative experiment is illustrated in Figure $6 A$. As can be seen, there are very large variations in eIPSC amplitudes in each triplet during DSI. Figure $6 B$ shows that, on average, for this pair, $\mathrm{v} / \mathrm{m}$ increased from $98 \mathrm{pA}$ in the control to $304 \mathrm{pA}$ during the first triplet period (5-15 sec after the end of the DSI-inducing pulse) and to $251 \mathrm{pA}$ in the second triplet period (20-30 sec after the end of the pulse). Both increases were highly significant ( $p<0.05 ; n=9$ DSI trials).

Other experiments invariably displayed an increase of $\mathrm{v} / \mathrm{m}$ during DSI, with a mean ratio to control values of $2.17 \pm 0.39$ $(n=6$; range, $1.16-3.28)$.

\section{Paired recordings with a $\mathrm{Cs}^{+}{ }^{+}$-rich presynaptic intracellular solution}

There are two plausible interpretations for the large enhancement of presynaptic variability during DSI, which was outlined by the results of the previous section. One explanation is that propagation failures significantly contributed to the reduced synaptic strength, as previously suggested (Alger et al., 1996). An alternative possibility is, however, suggested by examination of Equation 1 . If the release probability $p_{\text {ctl }}$ is close to 1 in control conditions Equation 1 predicts a severe reduction of the $\mathrm{v} / \mathrm{m}$ by the factor $1-p_{\mathrm{ctl}}$. During DSI, $p$ is reduced, and the $\mathrm{v} / \mathrm{m}$ would recover a much larger value. To test this latter possibility, we 
$\mathbf{A}$

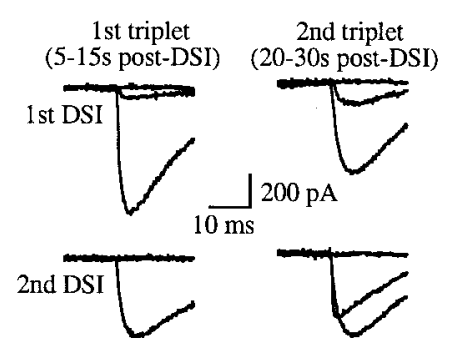

B

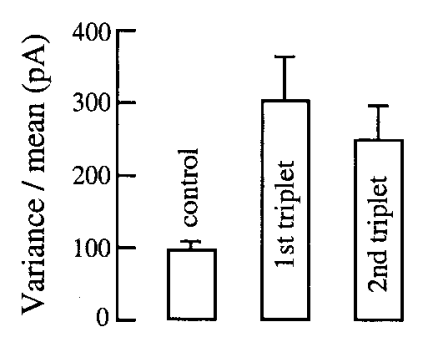

Figure 6. Amplitude fluctuations during DSI. $A$, To analyze the elPSC amplitude fluctuations, in each DSI, episode traces were grouped in two triplets: a first triplet corresponding to the evoked currents obtained 5,10 , and 15 sec after the DSI pulse and a second triplet corresponding to the currents obtained 20,25, and 30 sec after the DSI pulse. In each triplet, the mean, the variance, and the variance-to-mean ratio of the elPSCs were calculated; these results were compared with those obtained in control periods. Here, the raw postsynaptic traces for the two DSI triplets are depicted for two separate trials in the same experiment. Notice the extreme variability of the responses during this period of maximal DSI expression. B, Variance-to-mean ratios for the control periods (during which the mean eIPSC amplitude was $3.17 \mathrm{nA}$ ) and for the first and second triplets (with respective mean values of 0.35 and $0.47 \mathrm{nA}$ ). In this experiment, the variance-to-mean ratio increases threefold at the peak of the DSI period. Error bars indicate SEM for the various DSI trials performed in this experiment $(n=9)$.

needed to study DSI under various basal release modes. With this purpose, we examined DSI in pairs, in which a $\mathrm{Cs}^{+}{ }^{+}$-rich solution was placed in the pipette contacting the presynaptic interneuron; amphotericin $\mathrm{B}$ channels are highly permeable to $\mathrm{Cs}^{+}$, as they are to $\mathrm{K}^{+}$, so that equilibration was expected. With intracellular $\mathrm{Cs}^{+}$, we assumed that $p$ would be closer to 1 and that the comparison with the control situation would allow us to obtain at least an approximate estimate of $p_{\mathrm{ctt}}$. Another motivation for these experiments was that in the hippocampus it was reported that 4-aminopyridine (4-AP) significantly reduced the amount of the DSI of extracellularly evoked currents, indicating that 4-APsensitive $\mathrm{K}^{+}$channels could be one of the targets of DSI (Alger et al., 1996; Varma et al., 2002). We hoped that the selective block of presynaptic $\mathrm{K}^{+}$channels by $\mathrm{Cs}^{+}$dialysis in paired recordings would also shed light on this issue.

Previous results using presynaptic whole-cell recording showed that dialysis of the presynaptic interneuron with $\mathrm{Cs}^{+}$ resulted in a dramatic increase of the mean eIPSC amplitude and in a marked reduction of the $\mathrm{v} / \mathrm{m}$ (Vincent and Marty, 1996). We obtained similar results using perforated patch presynaptic recordings (Fig. 7). Figure 7, $A$ and $B$, illustrates a case in which the access conductance improved very slowly at the start of the experiment. This resulted in a slow exchange of the pipette $\mathrm{Cs}^{+}$for the cell $\mathrm{K}^{+}$, so that we could clearly distinguish the two conditions within the same recording. It can be seen that eIPSC amplitudes increased almost threefold on invasion of the presynaptic cell with $\mathrm{Cs}^{+}$. This was accompanied by a twofold increase in latency, an increase in rise time and decay time constants, and a considerable decrease in the coefficient of variation $(\mathrm{CV})$ of the response.

These general trends were confirmed when comparing average results of paired recordings using presynaptic $\mathrm{Cs}^{+}$versus $\mathrm{K}^{+}$ (Fig. 7C): the mean eIPSC amplitude increased to $2.72 \pm 0.44 \mathrm{nA}$ $(n=15$; compared with $1.00 \pm 0.25 \mathrm{nA} ; p \ll 0.05)$; the average latency increased to $3.97 \pm 0.36 \mathrm{msec}(n=13$; compared with the above value of $1.99 \pm 0.18 \mathrm{msec} ; p \ll 0.05)$; the decay time constant increased to $15.23 \pm 1.11 \mathrm{msec}(n=10$; compared with $12.1 \pm 0.90 \mathrm{msec} ; p<0.05)$; and the $\mathrm{CV}^{-2}$ increased to $141.5 \pm$ $35.5(n=15$; compared with $12.2 \pm 2.0$; $p \ll 0.05)$. However, the
A
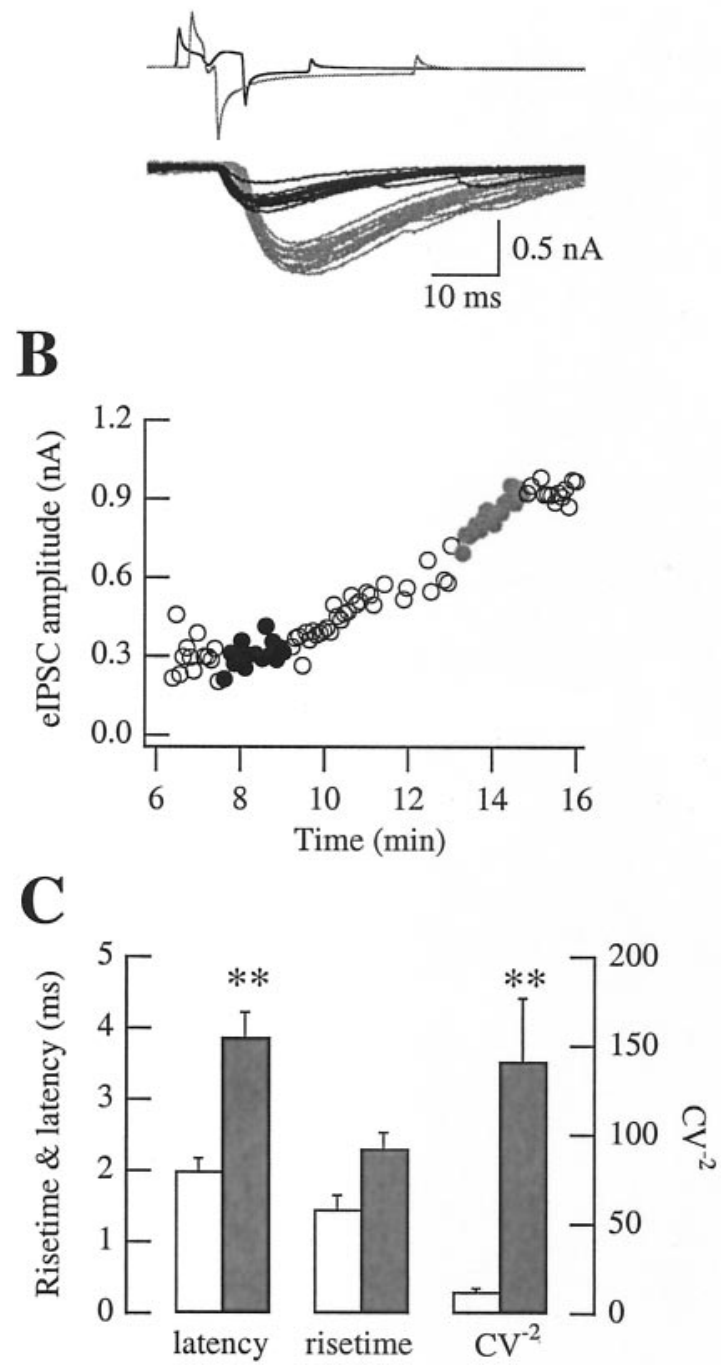

Figure 7. Effects of presynaptic $\mathrm{CS}^{+}$on elPSCS. $A$, In this paired recording, the access conductance through the amphotericin $B$ channels improved slowly, so that the diffusion of $\mathrm{Cs}^{+}$in the presynaptic cell could be followed as a function of time. Black traces represent results obtained at the beginning of the experiment, when the cell still retained its normal intracellular solution. Gray traces illustrate results recorded later during the slow equilibration of $\mathrm{Cs}^{+}$. Traces have been aligned with regard to the peak of the presynaptic action current. The presynaptic voltage-clamp protocol included a sequence of depolarizing and hyperpolarizing steps to ensure reliable stimulation of axonal action potentials and to accelerate axonal repolarization. This protocol was modified during the course of the experiment; the presynaptic depolarizing step was shortened, whereas the hypepolarizing one was lengthened as the access conductance improved with time. B, Time course of the elPSC amplitude for the same experiment. Black and gray dots represent the data corresponding to the raw traces in $A$. C, Summary results showing rise time, latency, and $\mathrm{CV}^{-2}$ in paired recordings using presynaptic $\mathrm{K}^{+}$(open bars; $n=16$ ) and in paired recordings using presynaptic $\mathrm{CS}^{+}$(filled bars; $n=15$ ). Differences in synaptic latency and $\mathrm{CV}^{-2}$ values are significant (indicated by asterisks), whereas the difference in rise time is not.

augmentation of the rise time did not quite reach statistical significance $(2.31 \pm 0.23$ compared with $1.47 \pm 0.19 \mathrm{msec} ; 0.05<$ $p<0.1$, Mann-Whitney $U$ test for all these parameters).

Moreover, with presynaptic $\mathrm{Cs}^{+}$, paired pulse depression developed; at a 100 msec interstimulus interval, the PPR was $63.1 \pm$ $4.6 \%(n=6)$. As previously reported for other synapses [in the goldfish (Waldeck et al., 2002) and in the calyx of Held (Wu and Borst, 1999)], the paired pulse protocol resulted in a significantly larger synaptic delay for the second eIPSC $(4.37 \pm 0.51 \mathrm{msec})$ 
A

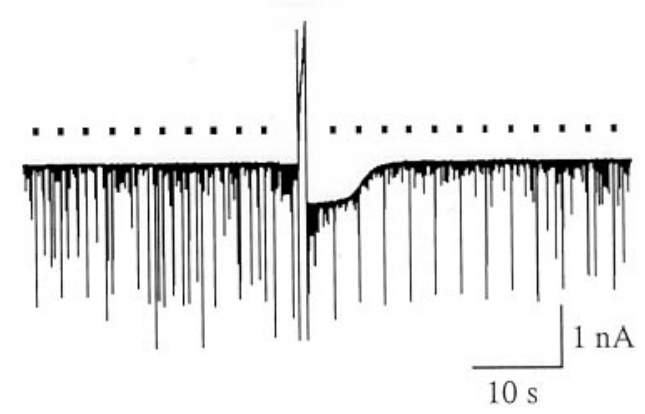

B
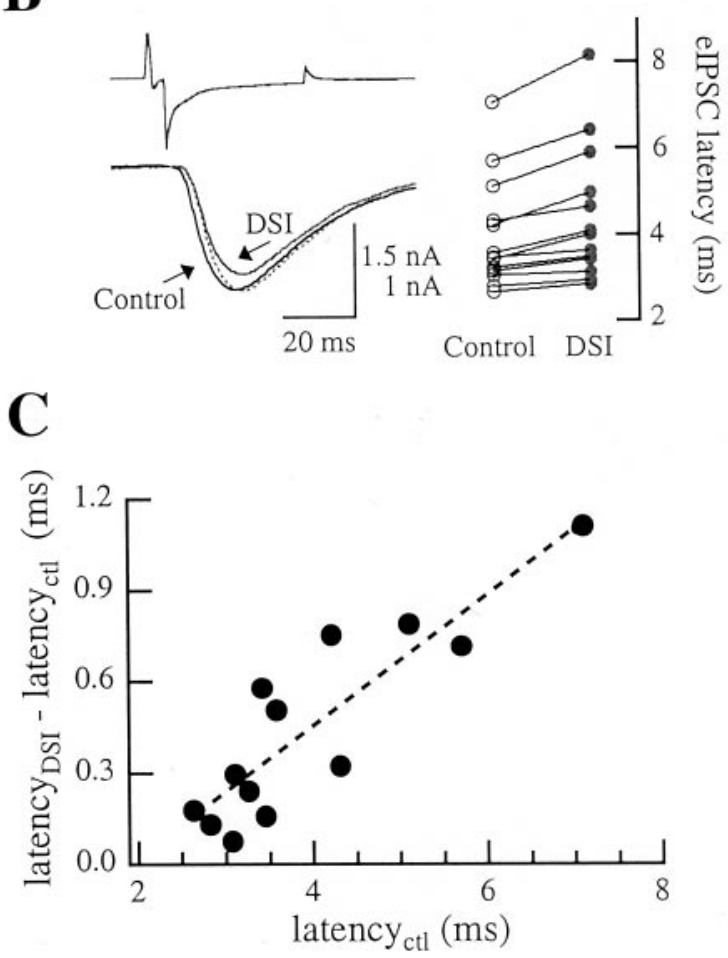

Figure 8. Effects of presynaptic $\mathrm{Cs}^{+}$on DSI $\mathrm{e}_{\mathrm{e}}$ A, eIPSCs elicited from a $\mathrm{Cs}{ }^{+}$-dialyzed interneuron (times of presynaptic stimulations indicated by dots) were much less affected by DSI than sIPSCs, which mostly arose from undialyzed interneurons. For this experiment, the maximal DSI amounted to $20.8 \pm 4.1 \%$ ( $n=5$ trials); after excluding the elPSCs from the analysis, the value of DSI ${ }_{s}$ was $75.7 \pm 1.3 \%$ ( $n=4$ trials). $B$, Left, Averaged traces in control runs (black) and during DSI (gray; recording different from that shown in $A$ ). The value of DSI was only $13.7 \pm 0.7 \%$ ( $n=4$ trials). The dotted gray trace illustrates the DSI average scaled to the amplitude of the control; notice the increase in synaptic latency. For this pair, the synaptic delay augmented from $7.05 \pm 0.05$ to $8.15 \pm 0.13 \mathrm{msec}(n=4)$. Right, Summary results showing a systematic latency increase during DSI. Each couple of connected points represents a paired recording. C, The DSI-associated latency increase is significantly correlated with the control latency value.

than for the first $(3.76 \pm 0.49 \mathrm{msec} ; n=5 ; p<0.05$, Wilcoxon's test).

\section{DSI in experiments with a $\mathrm{Cs}^{+}$-dialyzed interneuron}

DSI experiments as performed with a $\mathrm{Cs}^{+}$-dialyzed interneuron are depicted in Figure 8. Although sIPSCs, which originated primarily in synapses that were not exposed to presynaptic $\mathrm{Cs}^{+}$, underwent normal DSI, the amplitude of eIPSCs was little affected (Fig. $8 A, B$, traces from distinct pairs). On scaling, a clear latency increase typically appeared during DSI (Fig. $8 B$ ). On average, maximal DSI in $\mathrm{Cs}^{+}$amounted to $29.2 \pm 1.9 \%(n=15$; $p \ll 0.05$ when compared with the potassium experiments,
Mann-Whitney $U$ test), whereas synaptic delay increased from $4.0 \pm 0.4$ to $4.4 \pm 0.4 \mathrm{msec}(n=13 ; p \ll 0.05$, Wilcoxon's test).

Figure $8 C$ further shows that the latency increase was strongly correlated with the value pertaining to control conditions (Kendall's correlation coefficient, $\tau=0.64 ; n=13$; $p<0.01$ ); this suggests that a common mechanism underlies the increase in synaptic delay in presynaptic $\mathrm{Cs}^{+}$versus presynaptic $\mathrm{K}^{+}$and its augmentation during $\mathrm{DSI}_{\mathrm{e}}$ in $\mathrm{Cs}^{+}$conditions. Rise time and decay time constants were also found to increase significantly during DSI $_{\mathrm{e}}$ : to $2.35 \pm 0.23 \mathrm{msec}(n=15 ; p<0.05)$ and to $16.3 \pm 1.2$ $\operatorname{msec}(n=10 ; p<0.01$, Wilcoxon's test $)$, respectively.

As already mentioned, dialysis of the presynaptic neuron with $\mathrm{Cs}^{+}$resulted in a marked increase in the mean amplitude of synaptic currents. This increase presumably originated from a widening of the presynaptic action potential and the associated increase of presynaptic calcium transients. If these transients became sufficiently large to approach saturation of the release process, the modifications induced by DSI could translate into gradually smaller inhibition. Such a mechanism has been put forward to explain the reduction of hippocampal DSI in the presence of 4-AP (Varma et al., 2002). To explore this possibility, experiments with presynaptic $\mathrm{Cs}^{+}$were repeated after reducing the extracellular $\mathrm{Ca}^{2+}$ concentration to recover a mean eIPSC amplitude similar to that of control $\mathrm{K}^{+}$conditions (Fig. $9 A$, summary results in $B$ ). Under these conditions, the $\mathrm{v} / \mathrm{m}$, which had fallen to one-third of the control in $\mathrm{Cs}^{+}$and normal $\mathrm{Ca}^{2+}$, recovered to values indistinguishable from those in $\mathrm{K}^{+}$and normal $\mathrm{Ca}^{2+}$ (Fig. 9B, b). Likewise, the eIPSC rise time, which had increased in $\mathrm{Cs}^{+}$and normal $\mathrm{Ca}^{2+}$, decreased back to $2.09 \pm 0.33$ msec, a value similar to that observed in $\mathrm{K}^{+}(n=7 ; p>0.05$, Mann-Whitney $U$ test). Low extracellular calcium also reversed the depression obtained with the paired pulse protocol in normal calcium; the PPR was $104.9 \pm 9.6 \%(n=6$; $p \ll 0.05$, Wilcoxon's test). In contrast, the synaptic latency, which had increased in $\mathrm{Cs}^{+}$and normal $\mathrm{Ca}^{2+}$, was further increased to $4.36 \pm 0.53 \mathrm{msec}$ ( $n=7 ; p=0.05$, Wilcoxon's test).

As far as $\mathrm{DSI}_{\mathrm{e}}$ was concerned, it did increase in $\mathrm{Cs}^{+}$and low $\mathrm{Ca}^{2+}$ compared with $\mathrm{Cs}^{+}$and normal $\mathrm{Ca}^{2+}(46.6 \pm 6.9 \% ; n=8$; $p=0.02$, Wilcoxon's test), but it remained significantly lower than in $\mathrm{K}^{+}$and normal Ca ${ }^{2+}$ (Fig. 9B, $c$; $p<0.01$, Mann-Whitney $U$ test).

One possible shortcoming of low extracellular $\mathrm{Ca}^{2+}$ conditions is that they could lead to a decrease of $\mathrm{Ca}^{2+}$-induced endocannabinoid release. Therefore, we performed control experiments to compare $\mathrm{DSI}_{\mathrm{m}}$ in normal and low $\mathrm{Ca}^{2+}$. We found a value of $39.4 \pm 8.1 \%$ in low $\mathrm{Ca}^{2+}$, not significantly different from the $47.2 \pm 5.2 \%$ value obtained in normal $\mathrm{Ca}^{2+}$ in the same experiments ( $n=5 ; p>0.1$, Wilcoxon's test). This indicates that the amount of $\mathrm{Ca}^{2+}$ entering the postsynaptic Purkinje cell in low $\mathrm{Ca}^{2+}$ was still sufficient to saturate DSI and that the reduced calcium entry could not be held responsible for the smaller DSI in $\mathrm{Cs}^{+}$and low $\mathrm{Ca}^{2+}$ with respect to control conditions in $\mathrm{K}^{+}$.

Three conclusions can be drawn from these results. First, $\mathrm{Cs}^{+}$ interferes with the mechanisms underlying $\mathrm{DSI}_{\mathrm{e}}$; this is consistent with the hypothesis that $\mathrm{DSI}_{e}$ involves the modulation of $\mathrm{K}^{+}$ channels (Alger et al., 1996). Second, $\mathrm{DSI}_{\mathrm{e}}$ is actually reduced if the release process approaches saturation, as recently suggested on the basis of 4-AP experiments in the hippocampus (Varma et al., 2002); this is also in line with the notion that a primary target of DSI $\mathrm{e}_{\mathrm{e}}$ is the amplitude of presynaptic $\mathrm{Ca}^{2+}$ transients (Wilson et al., 2001; Diana et al., 2002). Third, it appears that a residual part of $\mathrm{DSI}_{\mathrm{e}}$ is insensitive to blockage of $\mathrm{K}^{+}$channels; this component could be linked to the modulation of voltage-dependent 
$\mathbf{A}$

\section{$\mathbf{a}$}

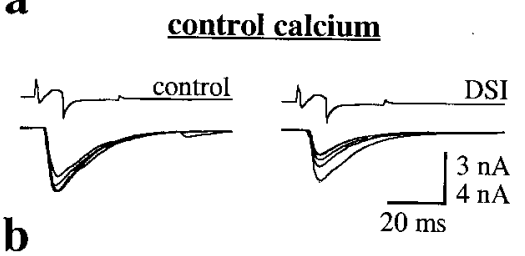

\section{low calcium}

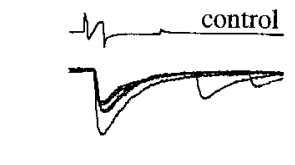

B

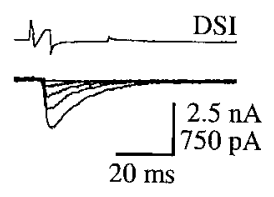

a

b
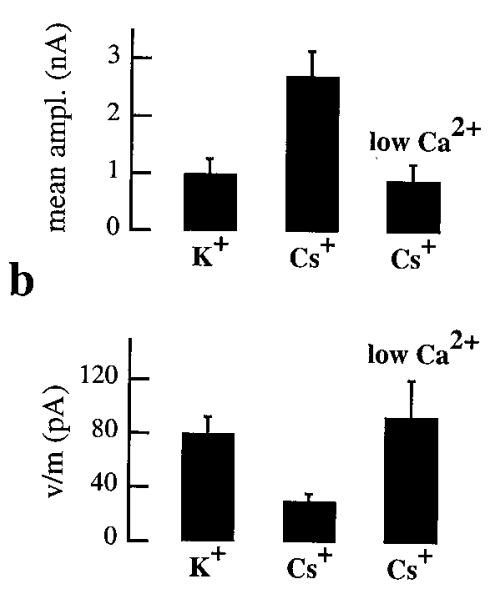

C

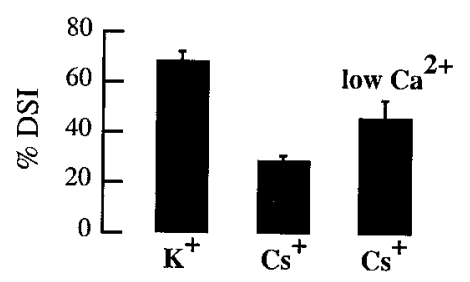

Figure 9. Partial DSI recovery on lowering extracellular calcium in paired recordings with intracellular $\mathrm{CS}^{+}$. $A$, Traces from a single paired recording with a $\mathrm{Cs}^{+}$-dialyzed presynaptic interneuron; two DSI trials are shown in normal $(2 \mathrm{~mm} ; a)$ and low $(1 \mathrm{~mm} ; b)$ extracellular calcium. Control currents are shown on the left, and DSI traces are shown on the right. Lowering calcium induced a strong reduction in the mean eIPSC amplitude but only a partial recovery of DSI $_{e}$, from $32.8 \pm 3.9 \%$ in control to $40.6 \pm 10.8 \%$ ( $n=4$ in both conditions). The value of DSI was monitored in the same trials (traces not shown); no statistical difference was found between control $(63.3 \pm 3.4 \%)$ and low-calcium $(56.2 \pm 3.2 \% ; p>0.10)$ conditions, suggesting that, in both cases, the Purkinje cell depolarizations led to the synthesis of similar amounts of endogenous cannabinoids to induce DSI. $B$, elPSC mean amplitudes $(a)$, variance-to-mean ratios $(b)$, and $D S I_{e}$ values $(c)$ shown in control pairs in which the presynaptic interneuron was dialyzed with $\mathrm{K}^{+}$, in pairs with presynaptic $\mathrm{Cs}^{+}$, and in pairs where the presynaptic cell was dialyzed with $\mathrm{Cs}^{+}$and the extracellular $\mathrm{Ca}^{2+}$ concentration was reduced to $1 \mathrm{~mm}\left(\mathrm{Cs}^{+}\right.$, low $\left(\mathrm{a}^{2+}\right) \cdot a$, The mean elPSC amplitude was similar in $\mathrm{K}^{+}(1.00 \pm 0.25 \mathrm{nA} ; n=22)$ and in $\mathrm{Cs}^{+}$ and low $\mathrm{Ca}^{2+}(0.90 \pm 0.30 \mathrm{nA} ; n=8 ; p>0.05)$ but was strongly increased in $\mathrm{Cs}^{+}$and normal $\mathrm{Ca}^{2+}(2.72 \pm 0.43 \mathrm{nA} ; n=15)$. $b$, The $\mathrm{v} / \mathrm{m}$ decreased from $80.2 \pm 12.4 \mathrm{pA}(n=22$ pairs) in $\mathrm{K}^{+}$to $30.8 \pm 5.3 \mathrm{pA}$ in Cs ${ }^{+}\left(n=15 ; p<0.05\right.$, Mann-Whitney $U$ test); in $\mathrm{Cs}^{+}$and low $\mathrm{Ca}^{2+}$, this parameter returned to $93.6 \pm 27.1 \mathrm{pA}$, which was statistically indistinguishable from the $\mathrm{K}^{+}$conditions $(n=8 ; p \gg 0.05)$. C, In $\mathrm{Cs}^{+}$and low $\mathrm{Ca}^{2+}{ }^{2}, \mathrm{DSI}_{\mathrm{e}}$ was still significantly lower than in $\mathrm{K}^{+}$but significantly higher than in $\mathrm{Cs}^{+}$and normal $\mathrm{Ca}^{2+}$.
$\mathrm{Ca}^{2+}$ currents (Wilson et al., 2001), to the inhibition of the exocytotic step, or to the modulation of the readily releasable pool, as found in other systems (Sakaba and Neher, 2001).

Finally, as explained in Discussion, these experiments also led us to suggest some hypotheses on the sources of the increased eIPSC variability during DSI in control $\mathrm{K}^{+}$conditions.

\section{Discussion}

\section{The various components of DSI}

This work allows a quantitative assessment of the various components of DSI. To determine the share of each component, we first note that mIPSCs amount to a surprisingly large proportion of the sIPSC frequency (47\%) and cumulative amplitude (21\%). These mIPSCs are, according to the results of Figure $1 B$, reduced by $43.3 \%$ during DSI. The frequency of presynaptic action potentials is reduced by $20 \%$ (Kreitzer et al., 2002), and, finally, paired recording experiments reveal that the amplitude of eIPSCs (including failures) decreases by $68.8 \%$ (Fig. 4). As shown in Appendix, these numbers can be combined together to predict the value of DSI ${ }_{s}$. The result is $68.4 \%$, which is in good agreement with the experimental value (64.2\%) obtained in Figure $1 \mathrm{~A}$.

A similar analysis can be performed on the frequency compo-

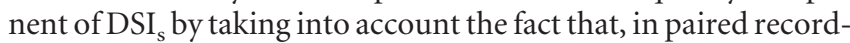
ings, the failure rate increases from 1.2 to $20.2 \%$ during DSI (Fig. 5). This allows us to predict a frequency component of $39.1 \%$ for $\mathrm{DSI}_{\mathrm{s}}$ also in very good agreement with the observed value of 39.9\% (Appendix). The excellent match between predicted and calculated parameters for $\mathrm{DSI}_{\mathrm{s}}$ indicates that our analysis correctly identifies the various components of DSI and their respective weights.

An interesting outcome of this analysis is the fact that mIPSCs contribute to $42 \%$ of the residual sIPSCs at the peak of DSI compared with $21 \%$ in the control (cumulative amplitude data). Thus, the relatively low sensitivity of mIPSCs to DSI translates into an increase of their weight to very significant proportions during DSI periods.

On the basis of the above analysis it is possible to ascribe proportions to the various components of DSI identified so far, namely, the decrease in mIPSCs, the decrease in presynaptic firing frequency, and the decrease in eIPSC amplitude. As shown in Appendix, these three processes contribute respectively to 13.4, 23.2 , and $63.4 \%$ of the reduction of sIPSCs during DSI.

\section{Trial-to-trial variation of presynaptic release signal during DSI}

One of the earliest proposals for the mechanism of DSI was that it involved propagation failures in the axon (Alger et al., 1996). This hypothesis is compatible with the finding that $\mathrm{DSI}_{\mathrm{s}}$ but not $\mathrm{DSI}_{\mathrm{m}}$ spreads along interneuron axons (Vincent and Marty, 1993), as well as with the demonstration that DSI inhibits presynaptic firing (Kreitzer et al., 2002). We found an increase in the failure rate during DSI, and we also found that the mean amplitude of nonfailing events was reduced (Fig. 3). These results could respectively reflect a total stop of propagation in the entire axonal tree and a selective propagation block in axon collaterals. Alternatively, or additionally, they could reflect a general reduction of the release probability within the classical framework of quantal theory.

To test the latter possibility, a quantitative analysis of the $\mathrm{v} / \mathrm{m}$ was performed, revealing a 2.17-fold increase in DSI compared with the control (Fig. 6). According to Equation 1, the decrease in release probability, $p$, which accompanies DSI, could account for at least part of the effect. If $p_{\mathrm{ctl}}$ and $p_{\mathrm{DSI}}$ represent the release 
probability in the control and DSI conditions, respectively, Equation 1 predicts an increase of the $\mathrm{v} / \mathrm{m}$ by the factor $\left(1-p_{\mathrm{DSI}}\right) /(1-$ $\left.p_{\mathrm{ctl}}\right)$. Experiments with presynaptic $\mathrm{Cs}^{+}$have a mean eIPSC amplitude that is 2.71-fold larger than in control conditions, so that $p_{\mathrm{ctl}}<1 / 2.71=0.37$. By applying Equation 1 to the mean and $\mathrm{v} / \mathrm{m}$ data in $\mathrm{Cs}^{+}$and normal $\mathrm{Ca}^{2+}$ and in $\mathrm{Cs}^{+}$and low $\mathrm{Ca}^{2+}$ (Fig. $9 B$, $a, b)$, one can calculate that the release probability in $\mathrm{Cs}^{+}$and low $\mathrm{Ca}^{2+}$ is 0.25 . This, together with the ratio of mean currents in control and in $\mathrm{Cs}^{+}$and low $\mathrm{Ca}^{2+}(1.04$; Fig. $9 B, a)$, gives an estimate of 0.26 for $p_{\mathrm{ctl}}$. Because the value of DSI $\mathrm{e}_{\mathrm{e}}$ is $0.688, p_{\mathrm{DSI}}$ is $0.26 * 0.312=0.08$, so that $\left(1-p_{\mathrm{DSI}}\right) /\left(1-p_{\mathrm{ct}}\right)=0.92 / 0.74=$ 1.24 . Thus the increase of the $\mathrm{v} / \mathrm{m}$ is too large to be simply attributable to a decrease in $p$. The failure of Equation 1, which is based on the analysis of quantal variance, to account for the results indicates that another source of variance participates in the fluctuations observed in $\mathrm{DSI}_{\mathrm{e}}$. The most likely explanation is that the presynaptic $\mathrm{Ca}^{2+}$ transients display significant trial-to-trial fluctuations during DSI $_{e}$. Two mechanistic interpretations can be offered. One would be that the presynaptic conductance changes responsible for the inhibition of firing (Kreitzer et al., 2002) make the invasion of presynaptic terminals unreliable, inducing trialto-trial variations in the presynaptic depolarizing waveform. This would be in line with the propagation failure hypothesis. The second option is suggested by the recent demonstration that ryanodine-sensitive presynaptic $\mathrm{Ca}^{2+}$ transients shape mIPSCs at this synapse (Llano et al., 2000). It could be that such transients elicit fluctuations in the action potential-evoked presynaptic signals, and that these fluctuations become more prominent during DSI. Thus, a definitive conclusion on the participation of propagation failures in DSI must await experiments with more direct approaches such as simultaneous somatic and terminal recording of the presynaptic interneuron during DSI.

\section{$\mathrm{K}^{+}$-selective conductance may be involved in DSI ${ }_{e}$}

CB1Rs have been reported to upregulate different types of $\mathrm{K}^{+}$ channels (Deadwyler et al., 1993; Mackie et al., 1995; Ho et al., 1999). The paired recording experiments in which presynaptic neurons were perfused with a $\mathrm{Cs}^{+}$-rich solution can be used to sort out the possible role of $\mathrm{K}^{+}$-selective conductances in $\mathrm{DSI}_{\mathrm{e}}$.

In experiments with presynaptic $\mathrm{Cs}^{+}, \mathrm{DSI}_{\mathrm{e}}$ was greatly reduced. Part of this effect could be ascribed to the fact that in $\mathrm{Cs}^{+}$, the release probability was close to 1 , so that the decrease in presynaptic $\mathrm{Ca}^{2+}$ transient presumably associated with $\mathrm{DSI}_{e}$ (Diana et al., 2002) was less effective than in the control. In addition, however, once the $\mathrm{Cs}^{+}$-associated amplitude increase was compensated by decreasing the extracellular $\mathrm{Ca}^{2+}$ concentration, $\mathrm{DSI}_{\mathrm{e}}$ remained significantly smaller than in the control (Fig. 9). This indicates that, as suggested earlier (Alger et al., 1996; Varma et al., 2002), $\mathrm{K}^{+}$channels are involved in $\mathrm{DSI}_{\mathrm{e}}$. These channels could be the same as the $\mathrm{K}^{+}$channels implicated in the regulation of presynaptic firing, because $\mathrm{Cs}^{+}$blocks the cannabinoid-induced outward current, which was suggested to mediate the inhibition of the interneuron spike rate (Kreitzer et al., 2002). However, the substantial amount of $\mathrm{DSI}_{\mathrm{e}}$ remaining in the $\mathrm{Cs}^{+}$and low $\mathrm{Ca}^{2+}$ conditions also indicates that a $\mathrm{K}^{+}$channel modulation is not the only mechanism at work under these conditions. An obvious candidate for the other component of DSI is a CB1R-mediated reduction in voltage-dependent $\mathrm{Ca}^{2+}$ currents, as suggested before (Wilson et al., 2001). Mechanisms acting on the synaptic release machinery and on the readily releasable pool of vesicles must also be considered, in view of the inhibition of the frequency of mIPSCs during cerebellar DSI, and as recently proposed also for hippocampal DSI (Varma et al.,
2002). Such mechanisms have actually been suggested in other systems in which synaptic plasticity was associated with increases in latency (Wu and Borst, 1999; Vyshedskiy et al., 2000), which we also observed during DSI ${ }_{\mathrm{e}}$ in the $\mathrm{Cs}^{+}$conditions (Fig. 8).

A strong correlation between the value of the control synaptic latency and its increase during DSI was also found (Fig. $8 C)$. By blocking $\mathrm{K}^{+}$conductances, $\mathrm{Cs}^{+}$increases the duration of action potentials. An augmentation in synaptic delay was previously observed in systems in which presynaptic action potentials were widened pharmacologically (in the neuromuscular junction; Benoit and Mambrini, 1970; Vyshedskiy et al., 2000) or by developmental mechanisms (in the calyx of Held; Taschenberger and von Gersdorff, 2000). Because the calcium inflow primarily takes place on the repolarization phase of an action potential, a delayed and slower repolarization translates into a delayed, longer-lasting, and larger synaptic current (for review, see Lin and Faber, 2002). All results obtained with $\mathrm{Cs}^{+}$conform to these predictions (Fig. 8). At the calyx of Held, latency strictly depends on the $\mathrm{Ca}^{2+}$ concentration increase (Bollmann et al., 2000; Schneggenburger and Neher, 2000) and on the amplitude of the $\mathrm{Ca}^{2+}$ currents (Wu and Borst, 1999) reached during presynaptic stimulation; the latency increase that is elicited by DSI in Cs ${ }^{+}$experiments is therefore most simply explained by a decrease in the amplitude of $\mathrm{Ca}^{2+}$ currents. The finding that, in $\mathrm{Cs}^{+}$experiments, decreasing the external $\mathrm{Ca}^{2+}$ concentration similarly leads to a further increase of latency is fully compatible with such a mechanism.

Having established, as we have done, the relative contributions of the different forms of synaptic inhibition making up DSI, the next important step in the DSI field will be to clarify the precise cellular mechanisms underlying these multiple pathways.

\section{Appendix}

Here we justify the finding that $\mathrm{DSI}_{\mathrm{s}}$, as measured in the experiments of Figure $1 \mathrm{~A}$, is accounted for by its various components as derived from mIPSC measurements and from the results of paired recordings.

\section{Frequency analysis}

The frequency of sIPSCs, $f_{\mathrm{s}}$, is the sum of the frequency of IPSCs occurring independently of presynaptic action potentials, $f_{\mathrm{m}}$, and of the frequency of events triggered by presynaptic action potentials, $f_{\mathrm{AI}}$ :

$$
f_{\mathrm{s}}=f_{\mathrm{m}}+f_{\mathrm{AI}} .
$$

The former frequency is assumed to be the same as the frequency of mIPSCs measured in the presence of TTX. The latter frequency is the product of the frequency of presynaptic action potentials, $f_{\mathrm{AP}}$, with the probability of having no transmission failure. Calling $F R$ the failure rate, we obtain:

$$
f_{\mathrm{AI}}=f_{\mathrm{AP}}(1-F R) .
$$

We call $\% f_{\mathrm{m}}$ the percentage of mIPSCs among sIPSCs:

$$
\% f_{\mathrm{m}}=f_{\mathrm{m}} /\left(f_{\mathrm{m}}+f_{\mathrm{AI}}\right) .
$$

The remaining fraction of mIPSC frequency during DSI is:

$$
1-D S I_{\mathrm{m}}=f_{\mathrm{m}, \mathrm{DSI}} / f_{\mathrm{m}, \mathrm{ct}},
$$

where $f_{\mathrm{m}, \mathrm{DSI}}$ and $f_{\mathrm{m}, \mathrm{ct}}$ are, respectively, the values of $f_{\mathrm{m}}$ during DSI and in the control. 

is:

Likewise, the remaining fraction of action potential frequency

$$
1-D S I_{\mathrm{AP}}=f_{\mathrm{AP}, \mathrm{DSI}} / f_{\mathrm{AP}, \mathrm{ct}},
$$

and the remaining fraction of sIPSC frequency is:

$$
1-D S I_{\mathrm{f}, \mathrm{s}}=f_{\mathrm{s}, \mathrm{DSI}} / f_{\mathrm{s}, \mathrm{ctl}} \text {. }
$$

Applying Equation 2 to both control and DSI conditions yields, in combination with Equation 7:

$$
1-D S I_{\mathrm{f}, \mathrm{s}}=\left(f_{\mathrm{m}, \mathrm{DSI}}+f_{\mathrm{AI}, \mathrm{DSI}}\right) /\left(f_{\mathrm{m}, \mathrm{ctl}}+f_{\mathrm{AI}, \mathrm{ctl}}\right) .
$$

Inserting Equations 3 and 4, we obtain:

$$
1-D S I_{\mathrm{f}, \mathrm{s}}=\left(f_{\mathrm{m}, \mathrm{DSI}}+f_{\mathrm{AP}, \mathrm{DSI}}\left(1-F R_{\mathrm{DSI}}\right)\right)^{*} \% f_{\mathrm{m}, \mathrm{ctl}} / f_{\mathrm{m}, \mathrm{ctl}} \cdot
$$

By inserting Equation 6 and applying Equation 3 to the control situation, we obtain:

$$
\begin{aligned}
& 1-D S I_{\mathrm{f}, \mathrm{s}}=\left(f_{\mathrm{m}, \mathrm{DSI}}+\right.\left(1-D S I_{\mathrm{AP}}\right)^{*} f_{\mathrm{AI}, \mathrm{ctl}} \\
&\left.\left(1-F R_{\mathrm{DSI}}\right) /\left(1-F R_{\mathrm{ctl}}\right)\right)^{\star} \% f_{\mathrm{m}, \mathrm{ctl}} / f_{\mathrm{m}, \mathrm{ctl}} \cdot
\end{aligned}
$$

This can be rearranged and combined with Equations 4 and 5 to yield:

$$
\begin{aligned}
& 1-D S I_{\mathrm{f}, \mathrm{s}}=\% f_{\mathrm{m}, \mathrm{ctl}}(\left.1-D S I_{\mathrm{m}}\right)+\left(1-\% f_{\mathrm{m}, \mathrm{ctl}}\right) \\
&\left(1-D S I_{\mathrm{AP}}\right)\left(1-F R_{\mathrm{DSI}}\right) /\left(1-F R_{\mathrm{ctl}}\right) .
\end{aligned}
$$

Inserting in this equation the proper parameter values $\left[\% f_{\mathrm{m}, \mathrm{ctl}}=\right.$ 0.47 (Gonzalez, Marty, and Llano, unpublished results); DSI $_{\mathrm{m}}=$ 0.433; $\mathrm{DSI}_{\mathrm{AP}}=0.20$ (Kreitzer et al., 2002); $\mathrm{FR}_{\mathrm{DSI}}=0.202$; and $\left.\mathrm{FR}_{\mathrm{ctl}}=0.012\right]$ gives $\mathrm{DSI}_{\mathrm{f}, \mathrm{s}}=39.1 \%$, very close to the experimental value given in Figure 1 (39.9\%).

\section{Cumulative amplitude analysis}

Similar equations can be derived for cumulative amplitudes. However, in this case, failures do not need to be considered, because the percentage of reduction of eIPSCs, DSI ${ }_{e}$, includes failures. The calculations yield:

$$
\begin{aligned}
& 1-D S I_{\mathrm{s}}=\% C_{\mathrm{m}, \mathrm{ctl}}(\left.1-D S I_{\mathrm{m}}\right)+ \\
&\left(1-\% C_{\mathrm{m}, \mathrm{ctl}}\right)\left(1-D S I_{\mathrm{AP}}\right)\left(1-D S I_{\mathrm{e}}\right),
\end{aligned}
$$

where $\mathrm{DSI}_{s}$ is the percentage of reduction of the cumulative amplitude of sIPSCs, and $\% c_{\mathrm{m}, \mathrm{ctl}}$ is the proportion of mIPSCs in the control cumulative amplitude. The numerical value of $\% c_{\mathrm{m}, \mathrm{ctl}}$ is 0.21 , and that of $\mathrm{DSI}_{\mathrm{e}}$ is $68.8 \%$. Entering these values in Equation 12 gives $\mathrm{DSI}_{\mathrm{s}}=68.4 \%$, close to the measured value of $64.2 \%$.

To calculate the share of the total inhibition that is attributable to the various components of DSI, we note that, of $1 \mathrm{nA}$ of cumulative amplitude of sIPSCs, mIPSC reduction amounts to $0.433 \times 0.21=0.0909 \mathrm{nA}$. The reduction attributable to action potential suppression amounts to $0.2 \times 0.79=0.158 \mathrm{nA}$. Finally the reduction attributable to eIPSCs after presynaptic firing is $0.684 \times 0.8 \times 0.79=0.432 \mathrm{nA}$. The proportions of the respective reductions are $13.4,23.2$, and $63.4 \%$.

\section{References}

Alger BE, Pitler TA, Wagner JJ, Martin LA, Morishita W, Kirov SA, Lenz RA

(1996) Retrograde signalling in depolarization-induced suppression of inhibition in rat hippocampal CAl cells. J Physiol (Lond) 496:197-209.

Ameri A (1999) The effects of cannabinoids on the brain. Prog Neurobiol 58:315-348

Benoit PR, Mambrini J (1970) Modification of transmitter release by ions which prolong the presynaptic action potential. J Physiol (Lond) 210:681-695.

Bollmann JH, Sakmann B, Borst JG (2000) Calcium sensitivity of glutamate release in a calyx-type terminal. Science 289:953-957.

Caillard O, Moreno H, Schwaller B, Llano I, Celio M, Marty A (2000) Role of the calcium-binding protein parvalbumin in short-term synaptic plasticity. Proc Natl Acad Sci USA (USA) 97:13372-13377.

Deadwyler SA, Hampson RE, Bennett BA, Edwards TA, Mu J, Pacheco MA, Ward SJ, Childers SR (1993) Cannabinoids modulate potassium current in cultured hippocampal neurons. Receptors Channels 1:121-134.

Diana MA, Levenes C, Mackie K, Marty A (2002) Short-term retrograde inhibition of GABAergic synaptic currents in rat Purkinje cells is mediated by endogenous cannabinoids. J Neurosci 22:200-208.

Glitsch M, Llano I, Marty A (1996) Glutamate as a candidate retrograde messenger at interneurone-Purkinje cell synapses of rat cerebellum. J Physiol (Lond) 497:531-537.

Glitsch M, Parra P, Llano I (2000) The retrograde inhibition of IPSCs in cerebellar Purkinje cells is highly sensitive to intracellular $\left[\mathrm{Ca} 2^{+}\right]$. Eur J Neurosci 12:987-993.

Ho BY, Uezono Y, Takada S, Takase I, Izumi F (1999) Coupling of the expressed cannabinoid $\mathrm{CB} 1$ and $\mathrm{CB} 2$ receptors to phospholipase $\mathrm{C}$ and $\mathrm{G}$ protein-coupled inwardly rectifying $\mathrm{K}+$ channels. Receptors Channels 6:363-374.

Katona I, Sperlagh B, Sik A, Kafalvi A, Vizi ES, Mackie K, Freund TF (1999) Presynaptically located CB1 cannabinoid receptors regulate GABA release from axon terminals of specific hippocampal interneurons. J Neurosci 19:4544-4558.

Kim J, Alger BE (2001) Random response fluctuations lead to spurious paired-pulse facilitation. J Neurosci 21:9608-9618.

Kreitzer AC, Regehr WG (2001) Cerebellar depolarization-induced suppression of inhibition is mediated by endogenous cannabinoids. J Neurosci $21: R C 174(1-5)$.

Kreitzer AC, Carter AG, Regehr WG (2002) Inhibition of interneuron firing extends the spread of endocannabinoid signaling in the cerebellum. Neuron 34:787-796.

Lin JW, Faber DS (2002) Modulation of synaptic delay during synaptic plasticity. Trends Neurosci 25:449-455.

Llano I, Leresche N, Marty A (1991) Calcium entry increases the sensitivity of cerebellar Purkinje cells to applied GABA and decreases inhibitory synaptic currents. Neuron 6:565-574.

Llano I, González J, Caputo C, Lai AF, Blayney LM, Tan YP, Marty A (2000) Presynaptic calcium stores underlie large-amplitude miniature IPSCs and spontaneous calcium transients. Nat Neurosci 3:1256-1265.

Mackie K, Lai Y, Westenbroek R, Mitchell R (1995) Cannabinoids activate an inwardly rectifying potassium conductance and inhibit Q-type calcium currents in AtT20 cells transfected with rat brain cannabinoid receptor. J Neurosci 15:6552-6561.

Pitler TA, Alger BE (1992) Postsynaptic spike firing reduces synaptic GABAA responses in hippocampal pyramidal cells. J Neurosci 12:4122-4132.

Pitler TA, Alger BE (1994) Depolarization-induced suppression of GABAergic inhibition in rat hippocampal pyramidal cells: $\mathrm{G}$ protein involvement in a presynaptic mechanism. Neuron 13:1447-1455.

Pouzat C, Hestrin S (1997) Developmental regulation of basket/stellate cell $\rightarrow$ Purkinje cell synapses in the cerebellum. J Neurosci 17:9104-9112.

Sakaba T, Neher E (2001) Calmodulin mediates rapid recruitment of fast-releasing synaptic vesicles at a calyx-type synapse. Neuron 32: $1119-1131$.

Schneggenburger R, Neher E (2000) Intracellular calcium dependence of transmitter release rates at a fast central synapse. Nature 406:889-893.

Tan YP, Llano I (1999) Modulation by $\mathrm{K}^{+}$channels of action potentialevoked intracellular $\mathrm{Ca}^{2+}$ concentrations rises in rat cerebellar basket cell axons. J Physiol (Lond) 520:65-78.

Taschenberger H, von Gersdorff H (2000) Fine tuning an auditory synapse for speed and fidelity: developmental changes in presynaptic waveform, EPSC kinetics, and synaptic plasticity. J Neurosci 24:9162-9173.

Tsou K, Mackie K, Sanudo-Pena MC, Walker JM (1999) Cannabinoid CB1 receptors are localized primarily on cholecystokinin-containing GABAergic interneurons in the rat hippocampal formation. Neuroscience 93:969-975.

Varma N, Brager DH, Morishita W, Lenz RA, London B, Alger B (2002) 
Presynaptic factors in the regulation of DSI expression in hippocampus. Neuropharmacology 43:550-562.

Vincent P, Marty A (1993) Neighboring cerebellar Purkinje cells communicate via retrograde inhibition of common presynaptic interneurons. Neuron 11:885-893.

Vincent P, Marty A (1996) Fluctuations of inhibitory postsynaptic currents in Purkinje cells from rat cerebellar slices. J Physiol (Lond) 494:183-199.

Vincent P, Armstrong CM, Marty A (1992) Inhibitory synaptic currents in rat cerebellar Purkinje cells: modulation by postsynaptic depolarization. J Physiol (Lond) 456:453-471.

Vyshedskiy A, Allana T, Lin JW (2000) Analysis of presynaptic $\mathrm{Ca}^{2+}$ influx and transmitter release kinetics during facilitation at the inhibitor of the crayfish neuromuscular junction. J Neurosci 20:6326-6332.
Waldeck RF, Pereda A, Faber DS (2002) Properties and plasticity of pairedpulse depression at a central synapse. J Neurosci 20:5312-5320.

Wilson RI, Nicoll RA (2001) Endogenous cannabinoids mediate retrograde signalling at hippocampal synapses. Nature 410:588-592.

Wilson RI, Kunos G, Nicoll RA (2001) Presynaptic specificity of endocannabinoid signaling in the hippocampus. Neuron 31:453-462.

Wu L-G, Borst JG (1999) The reduced release probability of releasable vesicles during recovery from short-term synaptic depression. Neuron 23:821-832.

Yoshida T, Hashimoto K, Zimmer A, Maejima T, Araishi K, Kano M (2002) The cannabinoid $\mathrm{CB} 1$ receptor mediates retrograde signals for depolarization-induced suppression of inhibition in cerebellar Purkinje cells. J Neurosci 22:1690-1697. 